\title{
Enhancement of Extinction Learning Attenuates Ethanol- Seeking Behavior and Alters Plasticity in the Prefrontal Cortex
}

\author{
ํㅣ Justin T. Gass, ${ }^{1}$ Heather Trantham-Davidson, ${ }^{1}$ Amanda S. Kassab, ${ }^{1}$ William B. Glen, Jr., ${ }^{1}$ M. Foster Olive, ${ }^{2}$ \\ and L. Judson Chandler ${ }^{1}$ \\ ${ }^{1}$ Department of Neurosciences, Medical University of South Carolina, Charleston, South Carolina 29425, and ${ }^{2}$ Department of Psychology, Arizona State \\ University, Tempe, Arizona 85287
}

Addiction is a chronic relapsing disorder in which relapse is often initiated by exposure to drug-related cues. The present study examined the effects of mGluR5 activation on extinction of ethanol-cue-maintained responding, relapse-like behavior, and neuronal plasticity. Rats were trained to self-administer ethanol and then exposed to extinction training during which they were administered either vehicle or the mGluR5 positive allosteric modulator 3-cyano- $N$-(1,3-diphenyl-1H-pyrazol-5-yl) or CDPPB. CDPPB treatment reduced active lever responding during extinction, decreased the total number of extinction sessions required to meet criteria, and attenuated cue-induced reinstatement of ethanol seeking. CDPPB facilitation of extinction was blocked by the local infusion of the mGluR5 antagonist 3-((2methyl-4-thiazolyl)ethynyl) pyridine into the infralimbic (IfL) cortex, but had no effect when infused into the prelimbic (PrL) cortex. Analysis of dendritic spines revealed alterations in structural plasticity, whereas electrophysiological recordings demonstrated differential alterations in glutamatergic neurotransmission in the PrL and IfL cortex. Extinction was associated with increased amplitude of evoked synaptic PrL and IfL NMDA currents but reduced amplitude of PrL AMPA currents. Treatment with CDPPB prevented the extinction-induced enhancement of NMDA currents in PrL without affecting NMDA currents in the IfL. Whereas CDPPB treatment did not alter the amplitude of PrL or IfL AMPA currents, it did promote the expression of IfL calcium-permeable GluR2-lacking receptors in both abstinence- and extinction-trained rats, but had no effect in ethanol-naive rats. These results confirm changes in the PrL and IfL cortex in glutamatergic neurotransmission during extinction learning and demonstrate that manipulation of mGluR5 facilitates extinction of ethanol cues in association with neuronal plasticity.

Key words: alcohol; extinction; glutamate; mglur5; MTEP; plasticity

\section{Introduction}

The goal of extinction-based therapies is to suppress drug seeking elicited by drug-associated memories. The neurocircuitry that underlies extinction of conditioned behaviors includes many of the same brain regions that are involved in normal learning and memory processes. For example, areas of prefrontal cortex (PFC) that are involved in fear conditioning are also implicated in drug conditioning (Millan et al., 2011; Milad and Quirk, 2012). Animal studies have shown the prelimbic $(\mathrm{PrL})$ cortex is a critical component in the circuitry of cocaine-seeking behavior (McFarland and Kalivas, 2001; Capriles et al., 2003; See, 2005; Di Pietro et

\footnotetext{
Received Dec. 6, 2012; revised April 17, 2014; accepted April 22, 2014

Author contributions: J.T.G., H.T.-D., and L.J.C. designed research; J.T.G., H.T.-D., A.S.K., and W.B.G. performed research; J.T.G. and M.F.O. contributed unpublished reagents/analytic tools; J.T.G. and H.T.-D. analyzed data; J.T.G. and L.J.C. wrote the paper.

This work was supported by the National Institutes of Health (Grant K99/R00AA020537 to J.T.G., Grants R01AA013852 and R01DA024355 to M.F.0., Grant F32AA021642 to W.B.G., and Grants R01AA010983 U01AA019967 to L.J.C.).

The authors declare no competing financial interests.

Correspondence should be addressed to Justin Gass, PhD, Department of Neurosciences, Medical University of South Carolina, 67 President Street, IOPN469, Charleston, SC 29425. E-mail: gass@musc.edu.

DOI:10.1523/JNEUROSCI.5616-12.2014

Copyright $\odot 2014$ the authors $\quad 0270-6474 / 14 / 347562-13 \$ 15.00 / 0$
}

al., 2006) and heroin-seeking behavior (LaLumiere and Kalivas, 2008; Rogers et al., 2008), whereas the infralimbic (IfL) cortex appears necessary for the expression of extinction behavior (Ovari and Leri, 2008; Peters et al., 2008a; Peters et al., 2008b). These converging lines of evidence suggest that the PrL cortex serves as an on switch for conditioned reward seeking, whereas the IfL cortex functions as an off switch for the expression of extinction behavior (Peters et al., 2009).

Extinction training also involves a number of neurochemical and molecular processes within the striatum (Schmidt et al., 2001; Self et al., 2004; Fuchs et al., 2006). Glutamatergic projections from the PrL cortex to the nucleus accumbens (NAc; Kalivas et al., 2006) core subregion may regulate drug seeking while glutamatergic projections from the IfL cortex to the NAc shell subregion are suggested to mediate extinction behavior (LaLumiere and Kalivas, 2008; Peters et al., 2008a; Peters et al., 2009; LaLumiere et al., 2010). It should be noted, however, that the orbitofrontal cortex has been shown to be involved in heroinseeking behavior (Fanous et al., 2012) and pathways shown to inhibit cocaine seeking may actually promote heroin-seeking behavior (Bossert et al., 2011; Bossert et al., 2012). 
Current implementations of exposure therapy have proven ineffective (Childress et al., 1993; Conklin and Tiffany, 2002). Therefore, the facilitation of extinction could serve as a novel therapeutic approach to increase the effectiveness of this inhibitory learning on relapse behavior. Extinction of conditioned fear (Kaplan and Moore, 2011) and cocaine-seeking (Botreau et al., 2006) behavior can be facilitated by the NMDA receptor partial agonist D-cycloserine (DCS). It has also been shown that the mGluR5 positive allosteric modulator (PAM) 3-cyano- $N$-(1,3diphenyl-1H-pyrazol-5-yl)) (CDPPB) enhances the extinction of cocaine memories (Gass and Olive, 2009; Cleva et al., 2011). These findings suggest that facilitating glutamatergic transmission during extinction training strengthens the acquisition of new memories formed during extinction training. The purpose of the present study was to determine whether CDPPB can facilitate the extinction of ethanol-cue-maintained responding in an operant paradigm and to assess the influence of facilitated extinction learning on cue-induced ethanol-seeking behavior. In addition, because extinction is a form of new and active learning and not the simple forgetting of previously learned contingencies, we also investigated the impact of extinction learning on glutamatergic transmission and structural plasticity in areas of the PFC.

\section{Materials and Methods}

\section{Animals}

Male Wistar rats (250-275 g upon arrival; Harlan Laboratories) were housed individually in standard polycarbonate cages. Access to food and water in the home cage was continuous throughout the experiment except during behavioral testing. The animal colony room was maintained on a 12:12 reverse light-dark cycle with lights off at 09:00 A.M. and experimental testing was performed during the dark portion of the cycle. All experimental procedures were conducted with the approval of the Institutional Animal Care and Use Committee at the Medical University of South Carolina within the guidelines set forth by the National Research Council's Guideline for the Care and Use of Mammals in Neuroscience and Behavioral Research (2003).

Of the 60 rats trained to self-administer ethanol in an operant task and then subsequently exposed to extinction training, nine were removed from the study before the commencement of extinction training or abstinence because they failed to successfully acquire ethanol self-administration. The criteria for successful acquisition of ethanol self-administration was $<20 \%$ variation in the number of active lever presses across three consecutive sessions. A minimum of 30 reinforcers per session and at least 12 sessions with $10 \%$ ethanol as the reinforcer were also required. A subset of rats that successfully acquired self-administration of ethanol was used for dendritic spines and electrophysiology experiments. Rats used in the dendritic spines experiment were trained to self-administer ethanol using the sucrose-fading paradigm, whereas rats in the electrophysiological experiments were trained using the pre-ethanol exposure technique. Due to modifications in the extinction procedures involved in the cue-induced ethanol-seeking experiments, an additional group of 12 rats was trained to self-administer ethanol (using the sucrose-fading paradigm) before being exposed to the extinction and reinstatement procedures. All rats in this group successfully acquired ethanol self-administration. An additional 24 rats were trained in the ethanol self-administration procedure (using the ethanol pre-exposure technique) for the microinjection experiments. All 24 of these rats successfully acquired the operant task.

\section{Self-administration apparatus}

Ethanol self-administration, extinction, and reinstatement test sessions were conducted in Plexiglas chambers $(32 \mathrm{~cm} \mathrm{~W} \times 25 \mathrm{~cm} \mathrm{D} \times 11 \mathrm{~cm} \mathrm{H}$, model ENV-008; Med Associates) located in melamine soundattenuating cubicles. Each cubicle was equipped with an exhaust fan to provide air circulation and to mask external noise. Mounted on one wall of the self-administration chamber were two response levers that flanked a liquid receptacle connected to a single-speed syringe infusion pump with polyethylene tubing. Responses on one lever, designated the active lever, resulted in delivery of the liquid reinforcer (see Self-administration procedures section), whereas responses on the other (designated inactive) lever had no programmed consequences. Located above the active lever was a $2.5-\mathrm{cm}$-diameter stimulus light that was illuminated for $1.5 \mathrm{~s}$ during each reinforcer delivery. Located atop the chambers was a house light to provide general illumination and a Sonalert speaker that emitted a tone $(2900 \mathrm{~Hz}, \sim 65 \mathrm{~dB})$ for $1.5 \mathrm{~s}$ during each reinforcer delivery. Chambers were interfaced to a PC that controlled experimental sessions and recorded data using commercially available software (MED Associates).

\section{Self-administration procedures}

Rats were trained to lever press on the active lever to receive a reinforcer on an FR1 schedule of reinforcement. Each active lever press activated the syringe pump to deliver $\sim 45 \mu \mathrm{l}$ of a liquid solution over a $1.5 \mathrm{~s}$ period. During reinforcer delivery, the stimulus light above the active lever was illuminated and the tone was presented. After each reinforcer delivery, a $4 \mathrm{~s}$ timeout period was initiated during which additional active lever presses were recorded but had no programmed consequences. In the experiments that assessed changes in dendritic spines, daily 30 min sessions were first conducted with sucrose $(10 \% \mathrm{w} / \mathrm{v})$ as the reinforcer $5 \mathrm{~d}$ per week. When response patterns stabilized (i.e., when the number of active lever presses per 30 min session varied $<15 \%$ across two consecutive sessions), the rats were trained to self-administer ethanol $10 \% \mathrm{v} / \mathrm{v}$ using a modified sucrose-fading procedure (Samson, 1986) that has been used previously in our laboratory (Gass et al., 2011; Sinclair et al., 2012). Briefly, ethanol was gradually added to the sucrose solution $(2 \%, 5 \%$, and then $10 \%$, with 1 week at each concentration) while sucrose was concurrently faded out of the solution $(10 \%, 5 \%, 2 \%$, then $0 \%)$ until rats were self-administering $10 \%$ ethanol in 30 min daily sessions conducted Monday through Friday. In the experiments that involved electrophysiology, rats were trained to self-administer ethanol by first exposing them to an intermittent 2-bottle choice drinking initiation paradigm for a period of 2 weeks. Three days per week, two bottles-one containing water and the other containing $20 \%$ ethanol-were placed on the cage. Twenty-four hours later, the bottles and the rats were weighed and the grams per kilogram bodyweight of ethanol consumed were calculated. The day after the last two-bottle choice session, the rats were placed in operant chambers and trained to self-administer a $20 \%$ ethanol solution in $30 \mathrm{~min}$ daily sessions. After stable responding for $20 \%$ ethanol ( $\sim 10-12$ sessions) was reached, the concentration of ethanol was reduced to $10 \%$ for the remaining sessions (12-16 sessions) to remain consistent with drinking using the sucrose-fading procedure. After stabilization of responding for $10 \%$ ethanol, blood samples $(20 \mu \mathrm{l})$ were taken from the tail vein using heparin-coated borosilicate capillary tubes immediately after a $30 \mathrm{~min}$ self-administration session for subsequent analysis of blood ethanol levels (see Blood ethanol level determination section). After an additional week of daily self-administration sessions, extinction training procedures commenced.

\section{Blood ethanol level determination}

Immediately after blood sample collection, samples were centrifuged at $10000 \times g$ for $10 \mathrm{~min}$ to obtain a plasma supernatant, which was then stored at $4^{\circ} \mathrm{C}$ for a maximum of $24 \mathrm{~h}$. Next, $5 \mu \mathrm{l}$ of plasma was used for determination of blood ethanol levels using an Analox AM-1 analyzer.

\section{Extinction procedures}

Extinction procedures and treatment with the mGluR5 PAM CDPPB commenced after maintenance criteria for the ethanol-only solution was reached. Extinction training was conducted in $30 \mathrm{~min}$ daily sessions in the presence of ethanol-associated cues (e.g., presentation of the light/ tone stimulus complex for $1.5 \mathrm{~s}$ after each active lever press, followed by a $4 \mathrm{~s}$ timeout), because it has been observed that such procedures produce drug-seeking behavior that is more resistant to extinction than that observed during extinction in the absence of drug-associated cues (Ranaldi and Roberts, 1996; Feltenstein and See, 2006). No liquid solution was given during extinction sessions and presses on the inactive lever during extinction were recorded but produced no programmed consequences.

In the experiments that examined dendritic spines, rats were randomly assigned to one of the following groups: extinction training with CDPPB 
treatment (Ext/CDPPB), extinction training without $\mathrm{CDPPB}$ treatment (Ext/Vehicle), forced abstinence with CDPPB treatment (Abst/CDPPB), and forced abstinence without CDPPB treatment (Abst/Vehicle). The days of forced abstinence were equal to the number of days of the extinction-training period. Rats used in the electrophysiological studies received the same group assignments.

For groups exposed to extinction training, 20 min before each extinction training session, rats were administered vehicle (10\% Tween 80$)$ or CDPPB $(30 \mathrm{mg} / \mathrm{kg}$, s.c.) according to their group assignment and returned to their home cages. The dose of CDPPB was based on our previous studies showing facilitation of extinction learning (Gass and Olive, 2009; Cleva et al., 2011). Rats were placed in the self-administration apparatus $20 \mathrm{~min}$ after treatment and lever-pressing behavior was recorded. Extinction criteria were considered to have been met when the number of active lever presses exhibited by an individual rat was $<20 \%$ (for 2 consecutive days) of those observed on the average of the last $2 \mathrm{~d}$ of active drug self-administration for that particular rat. Rats in the forced abstinence groups were brought into the testing area, given injections based on their group assignment, and then placed back into their home cages.

\section{Cue-induced reinstatement procedures}

Rats assigned to the cue-induced reinstatement condition were trained to self-administer ethanol using the sucrose-fading procedure. However, to reinstate ethanol seeking by ethanol cues, rats in this group were exposed to an extinction training procedure in which the cues remained off during sessions. Rats in this condition were assigned to either the Ext/CDPPB or Ext/Vehicle group. Twenty minutes before each session of extinction training, rats were administered vehicle $(10 \%$ Tween 80 ) or CDPPB (30 mg/kg, s.c.) according to their group assignment and returned to their home cages. All conditions and criteria for extinction remained the same except that the ethanol cues were not presented. During reinstatement test sessions, rats were placed in the operant chamber, the test session began, and the ethanol cue was presented one time. Lever presses were recorded and each press on the active lever resulted in a $1.5 \mathrm{~s}$ presentation of the light-tone stimulus that was previously paired with ethanol delivery followed by a $4 \mathrm{~s}$ timeout, but no ethanol was delivered. Reinstatement test sessions were $30 \mathrm{~min}$ in length and were conducted in the same operant self-administration chamber that was used during the maintenance and extinction phases.

\section{Electrophysiological recordings}

Acute brain slices containing PrL and IfL MPFC were prepared from rats that were anesthetized with isoflurane (Piramal Healthcare) $1 \mathrm{~d}$ after their final extinction session. The rat was decapitated, the brain was rapidly removed, and coronal slices were cut at $350 \mu \mathrm{m}$ thickness in ice-cold dissection ACSF solution containing the following (in mM): 200 sucrose, 1.9 potassium chloride $(\mathrm{KCl}), 1.2$ dibasic sodium phosphate $\left(\mathrm{Na}_{2} \mathrm{HPO}_{4}\right), 33$ sodium bicarbonate $\left(\mathrm{NaHCO}_{3}\right), 6$ magnesium chloride hexahydrate $\left(\mathrm{MgCl}_{2}\right), 0.5$ calcium chloride dihydrate $\left(\mathrm{CaCl}_{2}\right), 10$ D-glucose, and 0.4 ascorbic acid. Slices were incubated at $34^{\circ} \mathrm{C}$ for at least $1 \mathrm{~h}$ before recordings in incubation ACSF containing the following (in $\mathrm{mm}): 125$ sodium chloride $(\mathrm{NaCl}), 2.5 \mathrm{KCl}, 1.25$ monobasic sodium phosphate $\left(\mathrm{NaHPO}_{4}\right), 25 \mathrm{NaHCO}_{3}, 4 \mathrm{MgCl}, 1 \mathrm{CaCl}_{2}, 10$ D-glucose, 15 sucrose, and 0.4 ascorbic acid, continuously aerated with $5 \%$ carbon dioxide/95\% oxygen. After incubation, slices were transferred to a submerged recording chamber, held at $34^{\circ} \mathrm{C}$, and bathed with oxygenated recording ACSF containing the following (in $\mathrm{mM}$ ): $125 \mathrm{NaCl}, 2.5 \mathrm{KCl}, 25$ $\mathrm{NaHCO}_{3}, 2 \mathrm{CaCl}_{2}, 1.3 \mathrm{MgCl}_{2}, 10 \mathrm{D}$-glucose, and 0.4 ascorbic acid. The $\mathrm{pH}$ of all solutions listed above was adjusted to 7.3 using $\mathrm{NaOH}$ and osmolarity was measured to be $\sim 300 \mathrm{mOsm}$.

Recordings were made with a Multiclamp 700B amplifier (Molecular Devices), connected to a computer running Windows XP and Axograph $\mathrm{X}$ software, and later analyzed offline. All recordings were obtained from pyramidal neurons in layer $\mathrm{V}$ of the PrL or IfL cortex (Paxinos and Watson, 2005) identified with infrared-differential interference contrast optics and videomicroscopy. EPSCs were evoked using a tungsten bipolar stimulating electrode placed in layer $\mathrm{V}$ within $200 \mu \mathrm{m}$ of the cell being recorded. The stimulating electrode was connected to a Grass S88 stimulator and stimulus isolation unit.
For voltage-clamp experiments, recording electrodes (4-6 M $\Omega$ resistance) were filled with a solution containing the following (in $\mathrm{mM}$ ): 135 $\mathrm{CsCl}, 2 \mathrm{MgCl}_{2}, 10$ HEPES, 1 EGTA, $4 \mathrm{NaCl}, 2 \mathrm{NaATP}, 0.3$ Tris-GTP, and 10 phosphocreatine. $1 \mathrm{~mm}$ QX-314 Cl- was added to pipettes to block voltage-sensitive sodium channels from generating action potentials. The $\mathrm{pH}$ was adjusted to 7.3 using $\mathrm{KOH}$ and osmolarity was measured to be $\sim 285 \mathrm{mOsm}$. Series resistances $(<20 \mathrm{M} \Omega)$ and input resistances were continually monitored throughout the experiment via a $1 \mathrm{mV}(100 \mathrm{~ms})$ hyperpolarizing pulse. All experiments were performed in the presence of $100 \mu \mathrm{m}$ picrotoxin. Evoked NMDA (eNMDA) and evoked AMPA (eAMPA) currents were elicited by focal electrical stimulation in the presence of CNQX $(10 \mu \mathrm{M})$ or dl-APV $(50 \mu \mathrm{M})$, respectively. First, an input-output relationship was obtained by varying the intensity of stimulation from an amount that produced no response up to an amount that produced a response of maximal amplitude regardless of further increases in stimulus intensity. Then, the intensity was dialed down to generate a response that was $\sim 75 \%$ of the maximal amplitude. Next, evoked responses were measured at holding potentials from $-80 \mathrm{mV}$ to $+40 \mathrm{mV}$ in $10 \mathrm{mV}$ increments to construct an $I-V$ plot for the peak amplitude of the evoked currents. The eAMPA rectification index was obtained by calculating the slope of the $I-V$ relationship for each cell at negative holding potentials $(-80$ to $0 \mathrm{mV}$ ) and dividing that by the slope of the IV plot at positive holding potentials $(0$ to $+40 \mathrm{mV})$.

\section{Diolistic loading of dendritic spines}

Dendritic spine labeling followed previously reported methods (Kroener et al., 2012). Rats were anesthetized the day after the final extinction session and perfused with $0.1 \mathrm{M}$ phosphate buffer followed by $1.5 \%$ paraformaldehyde (PFA) in phosphate buffer. Brains were postfixed in 1.5\% PFA for $30 \mathrm{~min}$ before coronal sections $(150 \mu \mathrm{m})$ were prepared on a vibratome. Tungsten particles (1.3 $\mu \mathrm{m}$ diameter) were coated with DiI and delivered diolistically using a Helios Gene Gun (Bio-Rad) fitted with a polycarbonate filter (3.0 $\mu \mathrm{m}$ pore size; BD Biosciences). DiI was allowed to diffuse overnight at $4^{\circ} \mathrm{C}$ and sections were postfixed in $4 \%$ PFA for $1 \mathrm{~h}$. Confocal images (LSM 510; Zeiss) of first- and second-order basal dendrites of layer V pyramidal neurons in the PrL and IfL cortex were collected and a filament of the dendritic shaft and spines was created using Imaris XT (Bitplane) from deconvolved images. Dendritic spines were classified into four classes, long, mushroom, stubby, or filopodia, based on spine length (L), spine neck width $(\mathrm{WN})$, and spine head width (WH). Long spines were identified as having $\mathrm{L} \geq 0.5 \mu \mathrm{m}$ and $<3.0 \mu \mathrm{m}$; mushroom spines had $\mathrm{L}<3.5 \mu \mathrm{m}, \mathrm{WH}>0.35 \mu \mathrm{m}$, and $\mathrm{WH}>\mathrm{WN}$; stubby spines had $\mathrm{L}<0.5 \mu \mathrm{m}$; and filopodia were identified as having $\mathrm{L} \geq 3 \mu \mathrm{m}$. Analysis was performed on dendrites beginning $\sim 75 \mu \mathrm{m}$ distal to the soma; the length of each quantified dendrite was $50-60 \mu \mathrm{m}$. A total of 23 rats were used for dendritic spine analysis (Ext/CDPPB, $n=$ 6; Ext/Vehicle, $n=6$; Abst/CDPPB, $n=6$; Abst/Vehicle, $n=5$ ). A range of three to five neurons were analyzed from each brain region of each rat. For each neuron, three to five dendrites were analyzed and averaged for each neuron. Therefore, there was a range of 45-54 images analyzed for each experimental group. This method of analyzing dendritic spines is consistent with previously published studies (Shen et al., 2009; Kroener et al., 2012). From 3D confocal images of dye-filled dendritic processes, we analyzed the following parameters: dendritic length, dendritic mean diameter, total spine density, spine class density, spine class length, spine class terminal point diameter, spine class volume, and the terminal point volume (mushroom spines only).

\section{Microinjection cannula implantation}

A separate group of 24 rats were assigned to a microinjection experiment to test the ability of local administration of MTEP (an mGluR5 antagonist) in the IfL or PrL cortex to prevent the facilitating effects of CDPPB on the extinction of ethanol-seeking behavior. Rats were anesthetized with isoflurane vaporized in medical grade breathing air at a flow rate of $0.4 \mathrm{~L} / \mathrm{min}$ and placed in a stereotaxic instrument (Kopf Instruments). Bilateral microinjection guide cannulae [26 ga outer diameter (OD) (Plastics One) were aimed to terminate $1 \mathrm{~mm}$ dorsal to the IfL or PrL cortex. The stereotaxic coordinates used (in millimeters from bregma and skull surface) were as follows: for the IfL cortex: anterior/poste- 
A Extinction (Sucrose Fade)

B Extinction (Sucrose Fade)

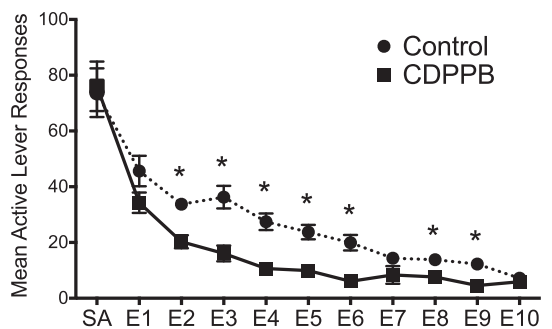

C

Extinction $(20 \%$ ET)

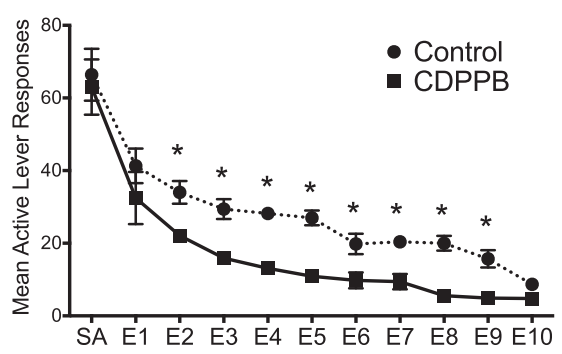

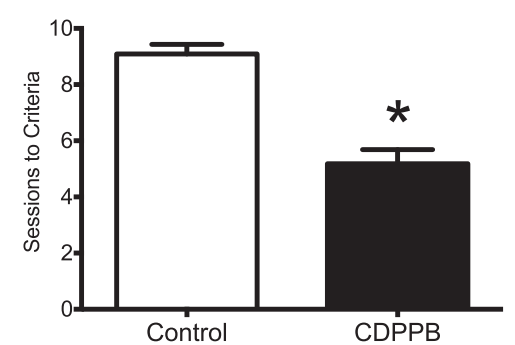

D

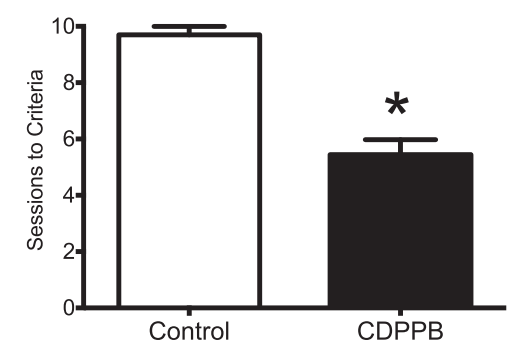

E

$20 \%$ vs. $10 \%$ ET

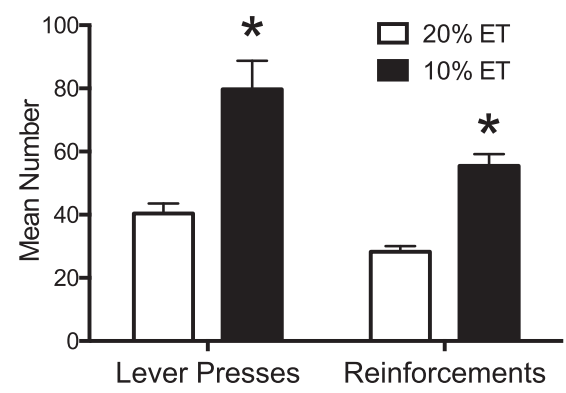

Figure 1. Treatment with CDPPB during extinction training facilitates the acquisition of extinction learning. Rats were trained to self-administer ethanol using a sucrose-fading technique (average ethanol consumption in 30 min was $1.18 \mathrm{~g} / \mathrm{kg} ; \boldsymbol{A}$ and $\boldsymbol{B} ; n=$ 11). A separate group of rats were trained to self-administer ethanol using a 2-bottle intermittent access initiation procedure (average consumption in $30 \mathrm{~min}$ was $1.11 \mathrm{~g} / \mathrm{kg} ; \boldsymbol{C}$ and $\boldsymbol{D} ; n=10)$. CDPPB resulted in a significant reduction in active lever responding on multiple days during extinction training and significantly decreased the number of sessions required to reach extinction criteria. ${ }^{*} p=0.001$. $\boldsymbol{E}$, In rats trained to self-administer ethanol, reducing the concentration of ethanol in the operant session from $20 \%$ to $10 \%$ resulted in a significant increase in both active lever responses $\left({ }^{*} p=0.001\right)$ and number of reinforcements received $\left({ }^{*} p=0.002 ; n=10\right)$.

rior +3.24 , medial/lateral \pm 0.6 , and dorsal/ventral -3.8 ; for the $\operatorname{PrL}$ cortex: anterior/posterior +3.24 , medial/lateral \pm 0.6 , and dorsal/ ventral -2.2 (Paxinos and Watson, 2005). Microinjection cannulae were secured to the skull with stainless steel screws and dental cement. Removable obturators ( 33 ga OD) were inserted in the full length of the guide cannulae to limit obstruction by tissue and contamination by external debris. The wound was treated with topical $2 \%$ xylocaine and $2 \%$ triple antibiotic ointments and sutured closed using 3-0 Vicryl sutures. After surgery, all rats were given carprofen $(2.5 \mathrm{mg} / \mathrm{kg}$, s.c., daily for $5 \mathrm{~d})$ for postoperative pain management. After recovery from surgery, rats were trained to self-administer ethanol as described in the Selfadministration procedures section.

\section{Microinjection procedures}

After successful acquisition of ethanol self-administration, rats were assigned to either an MTEP $(5 \mu \mathrm{g} / \mu \mathrm{l})$ or vehicle [artificial CSF (aCSF) group ( $n=6$ for each brain region/treatment; 24 rats total]. This dose of MTEP was chosen to maximize blockade of mGluR5 receptor activity and because we have shown previously that a $3 \mu \mathrm{g} / \mu \mathrm{l}$ dose can block the cue induced reinstatement of ethanol-seeking behavior (Sinclair et al., 2012). Bilateral microinjections were performed $25 \mathrm{~min}$ before each extinction session. Rats were lightly restrained and obturators were removed. Sterile 33 ga microinjection needles (Plastics One) were connected via microbore tubing to two $100 \mu \mathrm{l}$ syringes (Hamilton). Syringes were mounted on a micro-infusion pump (Harvard Apparatus) set to deliver fluids at a flow rate of 0.5 $\mu \mathrm{l} / \mathrm{min}$. Microinjection needles were inserted bilaterally to a depth $1 \mathrm{~mm}$ beyond the ventral tip of the guide cannula. Drug solutions were infused in a volume of $0.5 \mu \mathrm{l} /$ side over a $1 \mathrm{~min}$ period. Microinjection needles were left in place for an additional $60 \mathrm{~s}$ period to allow drug diffusion. Next, injectors were removed and obturators were replaced. Immediately after the microinjection, each rat received an injection of CDPPB (30 mg/kg, s.c.). After $20 \mathrm{~min}$, rats were placed in the operant chamber and the extinction session began. All conditions in the extinction session remained the same.

\section{Histological verification of microinjection sites}

Verification of cannula placement was determined using previously published methods (Gass et al., 2011). After behavioral procedures, rats were anesthetized with isoflurane and killed by decapitation. Brains were then removed, immersed in $10 \% \mathrm{v} / \mathrm{v}$ formalin for at least 1 week at $4^{\circ} \mathrm{C}$, and then immersed in a $30 \%(\mathrm{w} / \mathrm{v})$ sucrose solution for at least $72 \mathrm{~h}$ at $4^{\circ} \mathrm{C}$, followed by immersion in $15 \%(\mathrm{w} / \mathrm{v})$ sucrose for at least $72 \mathrm{~h}$ at $4^{\circ} \mathrm{C}$. Brains were then cut into $40 \mathrm{~mm}$ coronal sections on a cryostat (CM1900; Leica Microsystems), mounted onto microscope slides, and stained with cresyl violet for histological verification of cannula placement under light microscopy.

\section{Drugs}

CDPPB was custom synthesized by Chemir Analytical Services according to previously published methods (Lindsley et al., 2004; Kinney et al., 2005), purified to $>95 \%$ purity by liquid chromatography-mass spectrometry, and suspended in $10 \% \mathrm{v} / \mathrm{v}$ Tween 80 (SigmaAldrich). MTEP hydrochloride was purchased from Abcam and dissolved in sterile aCSF at a concentration of $5 \mu \mathrm{g} / \mu \mathrm{l}$.

\section{Statistical analyses}

Behavioral data from this study were analyzed based on the stage of the experiment using SPSS version 21.0 software and Prism version 6 software (GraphPad).

Extinction learning experiments. For experiments involving analysis of extinction behavior, lever presses on the last $2 \mathrm{~d}$ of active self-administration of $10 \%$ ethanol (i.e., maintenance) were averaged and compared with each day of extinction training using a mixed two-way repeated-measures ANOVA with treatment (control/CDPPB) as the between-subjects factor and experimental phase (maintenance/extinction session) as the withinsubjects factor. An independent-samples $t$ test was used to analyze the number of sessions required to reach extinction criteria. Separate ANOVAs were performed on the number of both active and inactive lever presses. Results from these analyses provided a statistical basis for determination of extinguished responding.

Cue-induced alcohol-seeking behavior experiment. For the analysis of reinstatement behavior, the number of lever presses recorded during 
A

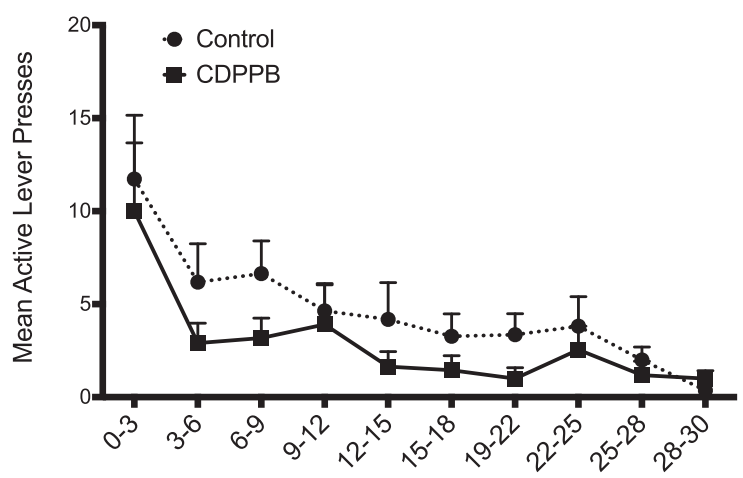

B

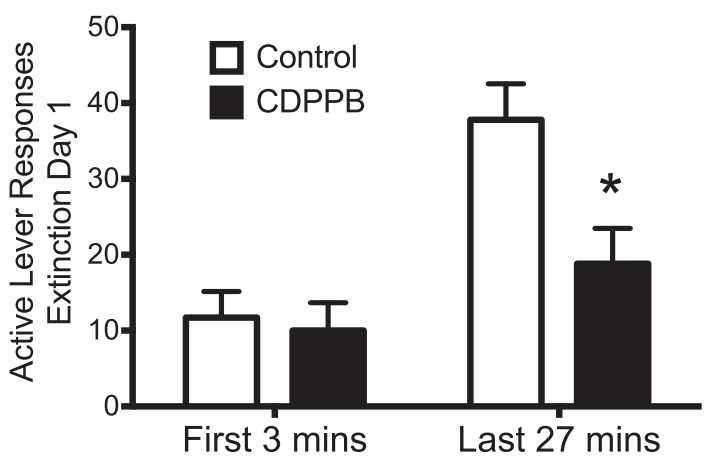

C

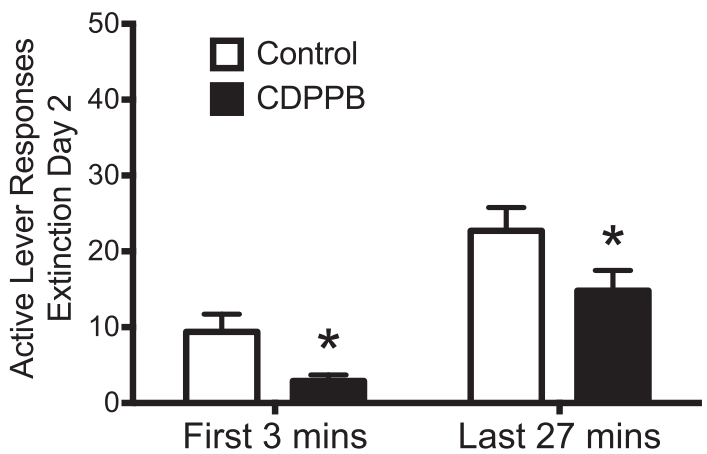

Figure 2. mGluR5-mediated facilitation of the extinction of ethanol self-administration represents new learning. $A$, Analysis of within-session responding during the first day of extinction revealed a treatment $\times$ time period interaction $(n=11)$. $\boldsymbol{B}$, Comparison of the binned responses revealed that $C D P P B$ did not alter responding on the previously active lever during the initial $3 \mathrm{~min}$ of the extinction session, but did significantly reduce responding on this lever during the remainder of the extinction session $\left({ }^{*} p=0.005\right)$. C, In contrast, analysis of the second day of extinction training revealed a significant group difference during the first 3 min of the extinction session, with CDPPB-treated animals responding significantly less during this time period. ${ }^{*} p=0.013$.

ethanol self-administration, the last day of the extinction training, and during the reinstatement test were compared using a mixed two-way ANOVA with treatment (control/CDPPB) as the between-subjects factor and experimental phase (self-administration, extinction, reinstatement) as the within-subjects factor. Separate ANOVAs were performed on the number of both active and inactive lever presses. Results from this analysis provided indication of successful reinstatement of ethanol-seeking behavior.

Electrophysiological experiments. Two-way $(2 \times 2$; treatment vs training) ANOVAs with corrections for multiple post hoc comparisons were used to test for significant effects of CDPPB and extinction learning on NMDA current peak amplitude, AMPA current peak amplitude, and AMPA current rectification index. For all experiments except the dendritic spine analysis, Holm-Sidak multiple-comparisons post hoc tests followed all ANOVAs.
A Extinction

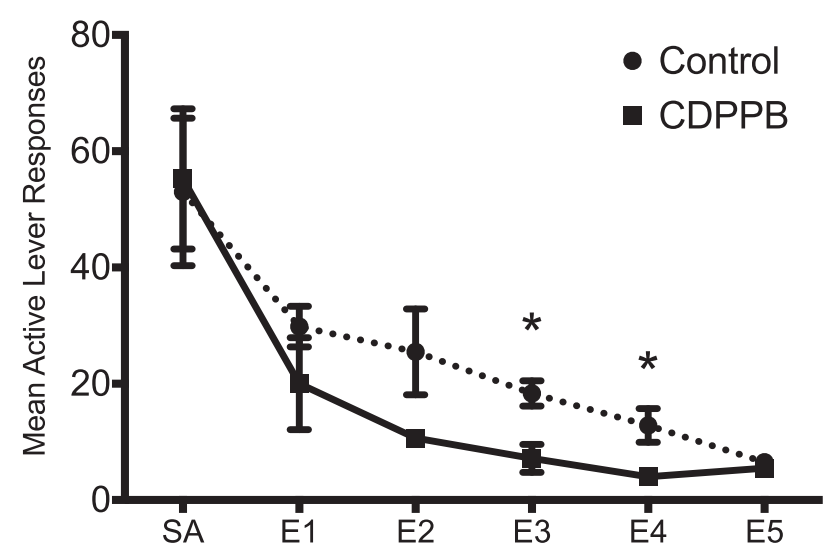

B Cue-Induced Reinstatement

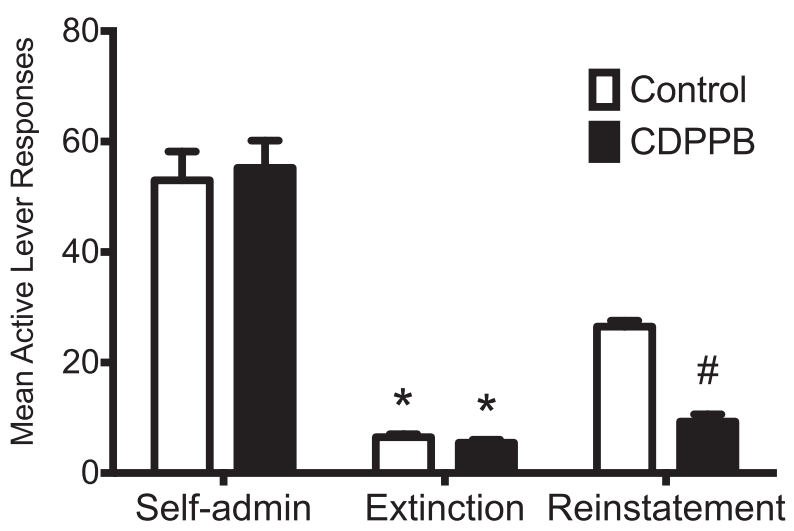

Figure 3. Treatment with CDPPB during extinction training attenuates cue-induced reinstatement of ethanol-seeking behavior. Rats from this experiment were trained to selfadminister ethanol using the sucrose-fading paradigm (average ethanol consumption in a 30 min session was $0.95 \mathrm{~g} / \mathrm{kg}$ ). On the day after the final day of extinction, rats were exposed to a session of cue-induced reinstatement of ethanol-seeking behavior by placing them in the operant chamber and exposing them to the ethanol cue. $\boldsymbol{A}$, Whereas the number of extinction sessions were truncated due to the absence of ethanol cues during extinction training, CDPPB significantly reduced active lever responding on multiple days. ${ }^{*} p<0.02$. B, Extinction training resulted in a significant reduction in active lever responding in both groups compared with self-administration levels. ${ }^{*} p<0.001$. Rats that displayed CDPPB-facilitated extinction learning exhibited significant attenuation of cue-induced reinstatement when exposed to ethanolassociated cues. \#p $=0.001 ; n=6$.

Dendritic spine experiments. Data obtained from dendritic spine measurements were analyzed using SAS (SAS Institute Inc.) using a previously published statistical technique (Kroener et al., 2012). The dendritic spine data were analyzed as a mixed model (SAS Proc Mixed) with a first-order autoregressive covariance matrix across the sequential slices within rats. This type of analysis allowed us to make statistical comparisons among the four groups in this experiment. Because no differences in spine density were observed between first- and second-order basal dendrites, the data were collapsed for subsequent analyses. All $p$-values $<0.05$ were considered statistically significant and all data are presented as mean \pm SEM. All $p$-values were given in exact numbers except for situations in which multiple comparisons resulted in several significant changes.

\section{Results}

Behavioral studies

In the first set of experiments, we investigated the effect of CDPPB administration on the extinction of ethanol cues in rats that 
A

B
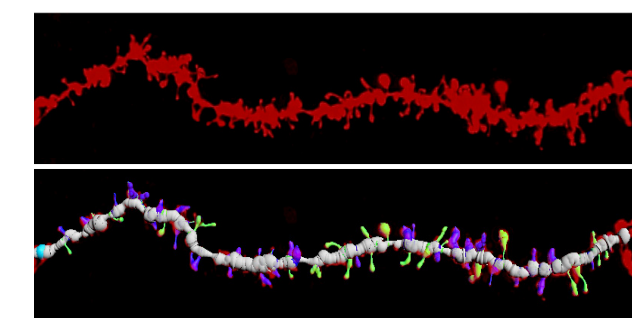

C IfL Total Spine Density

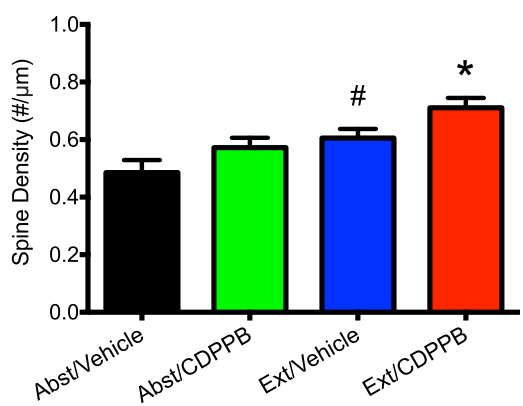

E PrL Total Spine Density

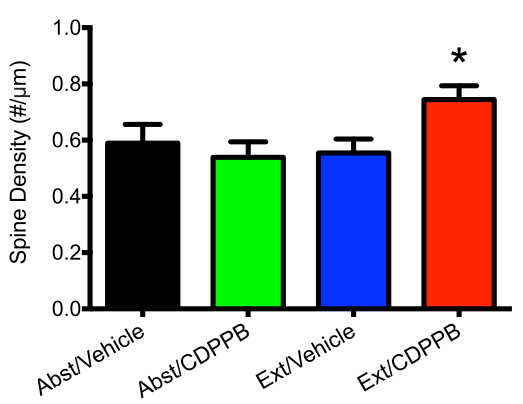

D IfL Spine Classes

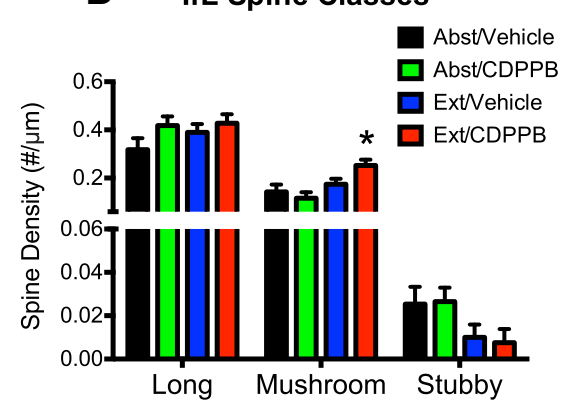

F PrL Spine Classes

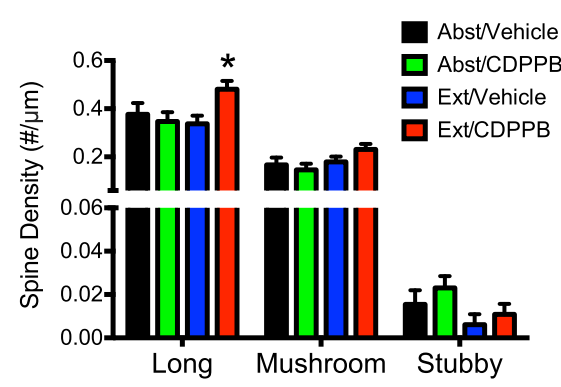

Figure 4. Facilitated extinction learning is associated with changes in dendritic spines in PrL and IfL cortex. Rats from this experiment were trained to self-administer ethanol using the sucrose-fading paradigm and were killed immediately after the final day of extinction. $\boldsymbol{A}$, Representative image of a dendrite of a layer 5 pyramidal neuron in the IfL cortex. $\boldsymbol{B}$, Color-coded image of the dendrite in $\boldsymbol{A}$ showing spine classification based on morphology. $\boldsymbol{C}$, Extinction training alone was associated with a significant increase in IfL spine density. $\# p=0.039$. CDPPB treatment further increased spine density during extinction training. ${ }^{*} p<0.038$. $D$, The increase in overall spine density in the IfL cortex resulted from an increase in the density of mushroom shaped spines. ${ }^{*} p<$ 0.03 . $\boldsymbol{E}$, Facilitated extinction learning was also associated with a significant increase in total spine density in the PrL. ${ }^{*} p<0.02$. $\boldsymbol{F}$, The increase in total spine density in the PrL cortex was the result of an increase in the density of immature, long type spines. ${ }^{*} p<0.02$. For the $\operatorname{Ext} / \operatorname{CDPPB}(n=6)$, Ext/Vehicle $(n=6), \operatorname{Abst} / \mathrm{CDPPB}(n=6)$, and Abst/Vehicle $(n=5)$ groups, 3-5 neurons were analyzed from the IfL cortex and PrL cortex for each rat and 3-5 dendrites were analyzed and averaged for each neuron.

had been trained to self-administer ethanol using a sucrosefading procedure. As shown in Figure $1 A$, administration of CDPPB 20 min before each daily extinction session resulted in a significant treatment $\times$ session interaction $\left(F_{(10,200)}=2.3, p=\right.$ $0.015 ; n=11)$. Post hoc analyses further revealed that rats treated with CDPPB had significantly fewer responses on the previously active lever compared with vehicle-treated rats on multiple extinction sessions $(p<0.001)$. Rats treated with CDPPB also required significantly fewer extinction sessions to reach extinction criteria compared with vehicle-treated rats $\left(t_{(20)}=6.4, p=0.001\right.$; Fig. 1B).

A potential concern with the sucrose-fading procedure is that initial responding for sucrose during the training period may produce a lasting memory trace for sucrose reward that could confound interpretation of the results. Therefore, in the next set of experiments, we used a two-bottle choice intermittent ethanol access procedure that does not involve sucrose to initiate drinking before training of operant ethanol self-administration. As was observed with rats that had been trained using the sucrose-fading procedure, analysis of extinction behavior using the intermittent access initiation procedure revealed a significant treatment $\times$ session interaction $\left(F_{(10,170)}=4.5, p=0.023 ; n=\right.$ 10 vehicle; $n=9$ CDPPB; Fig. $1 C)$. Post hoc analyses again showed that rats treated with CDPPB had significantly fewer responses on the previously active lever compared with vehicle-treated rats on multiple extinction sessions $(p<0.001)$. CDPPB also significantly reduced the number of extinction sessions needed to reach criteria compared with vehicletreated rats $\left(t_{(17)}=7.2, p=0.001\right.$; Fig. $1 D)$. There was no effect of treatment, session, or a treatment $\times$ session interaction with regard to inactive lever responding during the last $2 \mathrm{~d}$ of self-administration or extinction sessions. Together, these results demonstrate that positive allosteric modulation of mGluR5 facilitates the extinction of ethanol seeking. In addition, differences in the initial ethanol-training experience (i.e., sucrose versus intermittent) did not have any impact on either the rate of extinction of ethanol selfadministration $(p>0.05)$ or the effect of CDPPB $(p>0.05)$.

Additional analyses of the drinking behavior within the two-bottle intermittent access groups revealed that the concentration of ethanol significantly altered the rats' responding rates. There was a significant main effect of ethanol concentration $\left(F_{(1,36)}=40.8, p=0.001\right)$, but no significant interaction between ethanol concentration and type of responding (lever presses or number of reinforcements). When the concentration of ethanol was reduced from $20 \%$ to $10 \%$, there was a significant increase in the number of active lever presses $(p=0.001)$ and the number of reinforcers $(p=$ $0.002 ; n=10$; Fig. $1 E$ ). This suggests that the rats adjusted their level of ethanol self-administration based upon its behaviorally reinforcing effects.

To determine whether the CDPPB-induced increase in the rate of extinction of ethanol self-administration reflected new learning as a function of the failure to receive ethanol in response to pressing the previously active lever, we next investigated the within-session time course of responding in 3 min time bins during the first day of extinction. As shown in Figure 2A, CDPPB reduced active lever responding throughout the extinction session. Statistical analysis revealed a significant treatment $\times$ time period interaction $\left(F_{(1,38)}=4.3, p=0.046 ; n=11\right)$. Importantly, whereas CDPPB did not alter responding on the previously active 
lever during the initial 3 min of the extinction session, there was a significant reduction of responding on the previously active lever during the remainder of the extinction session ( $p=0.005$; Fig. $2 B$ ). In addition, analysis of the second day of extinction training revealed a main effect of time period $\left(F_{(1,38)}=28.9, p=0.001\right)$. During the first $3 \mathrm{~min}$ of the extinction session, CDPPB-treated rats responded significantly less during this time period $(p=0.013)$ and during the remainder of the session ( $p=0.045$; Fig. $2 C$ ). These results are consistent with the suggestion that CDPPB enhancement of extinction responding reflects new learning in response to the lack of reward delivery during the initial period of lever pressing. They also show that the CDPPB-induced reduction in active lever responding was not due to nonspecific motor effects, which is in agreement with previous studies investigating the effect of CDPPB on extinction of cocaine-seeking behavior (Cleva et al., 2011) and memory (Reichel et al., 2011).

In the next set of experiments, we investigated whether CDPPB enhancement of extinction learning alters subsequent cue-induced reinstatement of ethanolseeking behavior. For these experiments, the discrete cues (light and tone) were left off during the extinction period so that they could be used for cue-induced reinstatement. As expected, the number of sessions required for rats to reach extinction criteria when the discrete cues were not extinguished was reduced from 10 (Fig. $1 A, C$ ) to five sessions (Fig. 3A). Statistical analysis revealed a significant session $\times$ group interaction $\left(F_{(5,50)}=6.9\right.$, $p=0.018 ; n=6)$. Consistent with results obtained when the discrete cues were extinguished, CDPPB again was observed to significantly reduce responding on the previously active lever during extinction sessions 3 and 4 ( $p<0.02$; Fig. $3 A)$. Analysis of the reinstatement data indicated a significant treatment $\times$ phase interaction $\left(F_{(2,30)}=5.9, p=0.007\right)$. Specifically, whereas the groups did not differ during self-administration or after extinction training $(p>$ $0.05)$, exposure to the discrete cues after extinction training resulted in a significant increase in responding on the previously active lever ( $p=0.001$; Fig. $3 B)$. However, this increase was not present in rats that had received CDPPB during extinction training. This suggests that CDPPB enhancement of extinction learning results in reduced sensitivity to subsequent cue-induced reinstatement of ethanol-seeking behavior.

\section{Dendritic spine studies}

For analysis of dendritic spines in the PrL and IfL cortex, we limited our analysis to the basal dendrites of layer 5 pyramidal

A

B

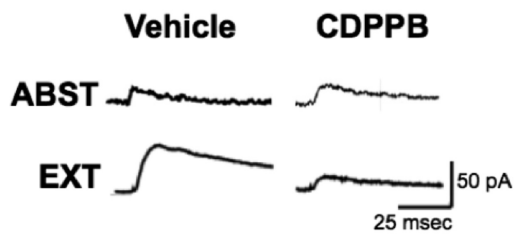

D
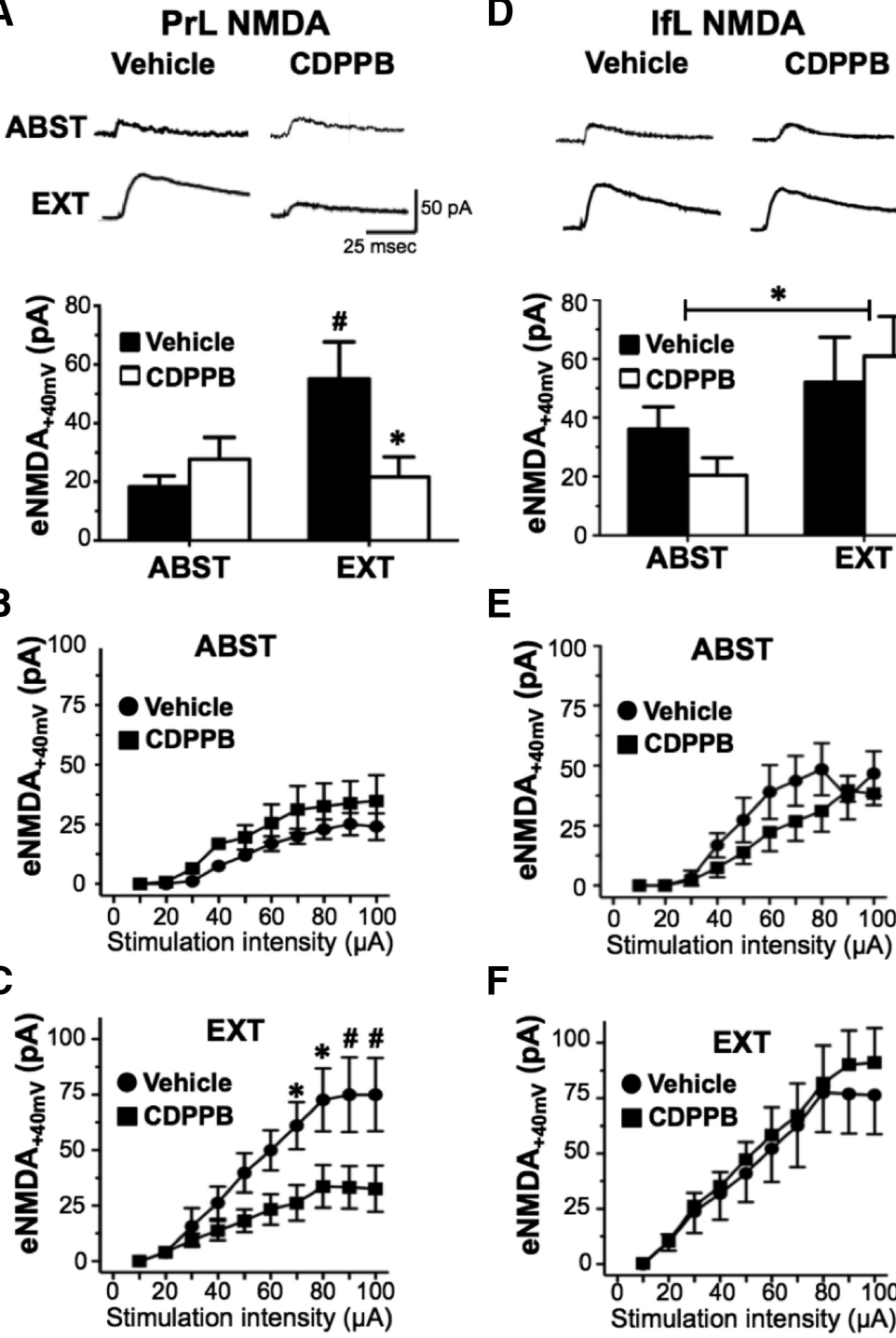

$\mathbf{F}$
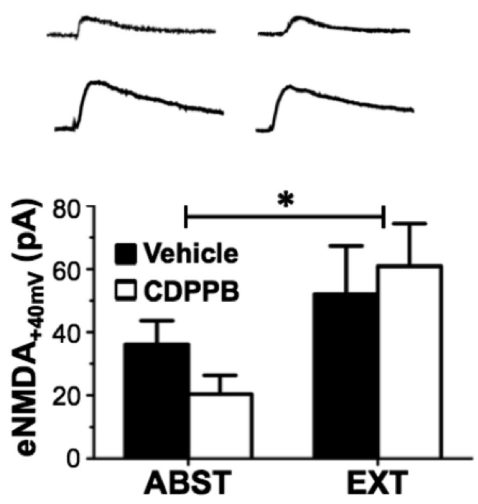

E

Figure 5. CDPPB reversed extinction-induced enhancement of eNMDA currents in the PrL but not the IfL cortex. Rats were trained to self-administer ethanol using an ethanol pre-exposure paradigm and then administered vehicle or CDPPB during abstinence (ABST) or extinction training (EXT). A, CDPPB did not significantly alter the amplitude of eNMDA currents in the PrL cortex of ABST rats. However, EXT enhanced eNMDA currents in Vehicle treated animals $(\#, p=0.033)$ and this increase was prevented by CDPPB treatment $\left({ }^{*} p=0.037\right)$. $\boldsymbol{B}$, Input-output curves for vehicle versus CDPPB from ABST rats were not significantly different. $\boldsymbol{C}$, In contrast, the input-output curves for EXT where significantly different at higher stimulation intensity. Symbols indicate significant difference from respective controls. ${ }^{*} p<0.033$; $\# p<0.008$. $\boldsymbol{D}$, In the IfL cortex, there was a main effect of extinction training (indicated by an asterisk above the bar; $p=0.035$ ), but this increase as not altered by CDPPB treatment. $\boldsymbol{E}, \boldsymbol{F}$, There were no significant differences in the input-output relationship of eNMDA currents between any of the drug treatment and training conditions in IfL cortex ( $n=6$ for all groups except EXT/CDPPB, for which $n=7$ ).

neurons. For the Ext/CDPPB $(n=6)$, Ext/Vehicle $(n=6)$, Abst/ CDPPB $(n=6)$, and Abst/Vehicle $(n=5)$ groups, 3-5 neurons were analyzed from each rat and 3-5 dendrites were analyzed and averaged for each neuron. Statistical analyses of the results revealed that, within the IfL cortex, there were significant differences among the four treatment groups in overall spine density $\left(F_{(3,17)}=6.1, p=0.005\right)$. Post hoc analyses showed that rats that underwent extinction training in combination with the vehicle treatment (Ext/Vehicle) had a significant increase in IfL cortex spine density compared with the forced abstinence (Abst/Vehicle) group ( $p=0.039$; Fig. $4 C$ ). This extinction-associated increase in spine density was further enhanced in rats that had undergone CDPPB-facilitated extinction learning. Specifically, 
A

\section{A}

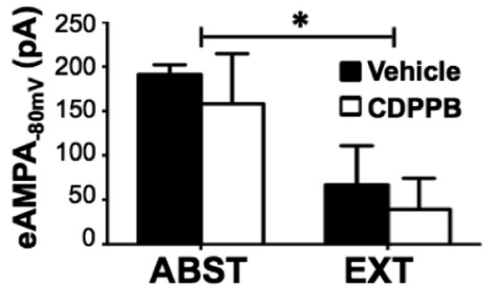

B

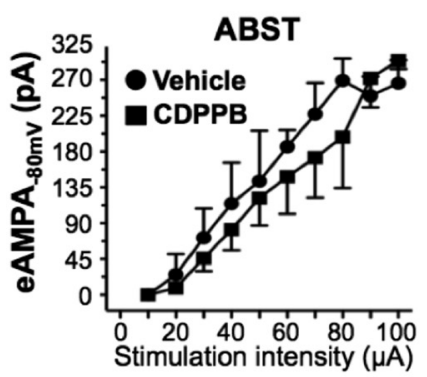

C

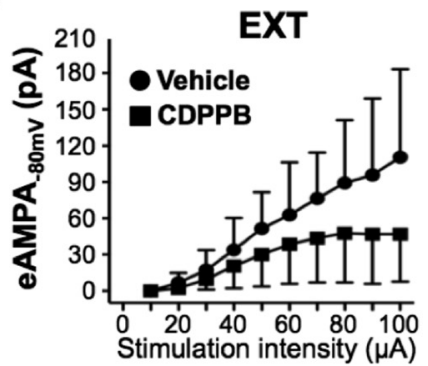

D

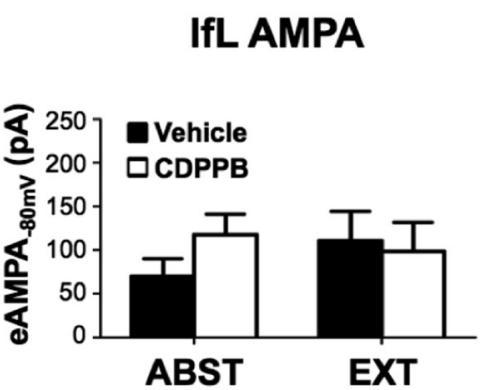

$\mathrm{E}$

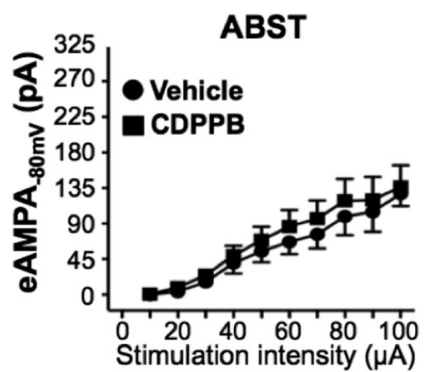

$\mathbf{F}$

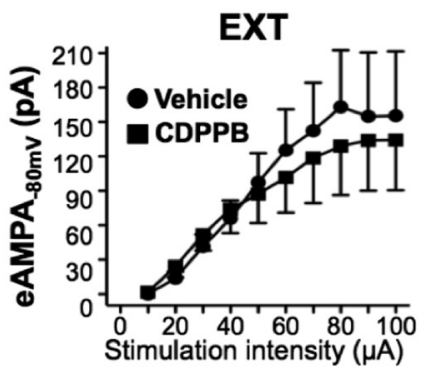

Figure 6. CDPPB did not alter extinction-induced decreases in eAMPA currents in PrL slices. Rats were trained to self-administer ethanol using an ethanol pre-exposure paradigm and then administered vehicle or CDPPB during abstinence (ABST) or extinction training (EXT). A, Whereas extinction training significantly decreased the amplitude of eAMPA currents in the PrL cortex when measured at a holding potential of $-80 \mathrm{mV}$ ( $p=0.011$; indicated by an asterisk above the bar), daily injections of CDPPB did not alter evoked AMPA currents in either the ABST or EXT groups $(n=6)$. B, $C$, In the PrL cortex, there were no differences between vehicle and CDPPB in the input-output relationship of eAMPA currents in either the ABST or EXT groups. $D$, In the IfL cortex, neither extinction training nor CDPPB altered the amplitude of eAMPA currents measured at a holding potential of $-80 \mathrm{mV}(n=6) . \boldsymbol{E}, \boldsymbol{F}$, The input-output relationships of eAMPA currents were not significantly different between vehicle and CDPPB in either the ABST or EXT groups.

rats in the Ext/CDPPB group had a significant increase in overall IfL spine density compared with the Abst/Vehicle $(p=0.001)$, Abst/CDPPB $(p=0.011)$, and Ext/Vehicle $(p=0.037)$ groups (Fig. $4 C$ ). In contrast, there was a slight but nonsignificant increase in the total density of dendritic spines in the IfL cortex in the Abst/CDDPB group versus the Abst/Vehicle group ( $p=$ $0.14)$.

To expand the analysis of structural plasticity, we next measured changes in spine morphology and classified the density of spines based upon their morphological classification. This analysis revealed that the increase in overall spine density in the IfL cortex of rats that displayed facilitated extinction was due in large part to an increase in the number of mature, mushroom spines $\left(F_{(3,17)}=5.7, p=0.007 ; p<0.03\right.$; Fig. $\left.4 D\right)$. There were no other significant differences among the groups in density of the other spine classes.

Within the PrL cortex, there were also significant differences among the four groups in overall spine density $\left(F_{(3,17)}=3.6, p=\right.$ $0.039)$. Post hoc analyses showed that facilitated extinction was associated with a significant increase in PrL cortex spine density compared with the other groups $(p<$ 0.02; Fig. $4 E$ ), an effect that appeared to result from a significant increase in long spine density $\left(F_{(3,17)}=3.6, p=0.035\right.$; Fig. $4 F)$. Together, these results demonstrate the facilitated extinction learning is associated with structural plasticity in both the IfL and PrL cortex.

\section{Electrophysiology studies}

Based on our observation that CDPPB enhanced extinction learning and attenuated cue-induced reinstatement of responding and on the observation of alterations of dendritic spines in the PrL and IfL cortex, we next performed whole-cell patch-clamp recordings in layer $\mathrm{V}$ pyramidal neurons in the PrL and IfL cortex to determine whether CDPPB facilitation of extinction was associated with changes in AMPA and NMDA currents. For these studies, acute mPFC slices were obtained from saline- and CDPPB-treated rats either $1 \mathrm{~d}$ after the last extinction session or after 8-10 d of abstinence. As shown in Figure $5 A$, recording of eNMDA currents (measured at a holding potential of +40 $\mathrm{mV}$ ) in the PrL cortex revealed a significant treatment $\times$ training interaction $\left(F_{(1,19)}=7.0, p=0.016\right.$; Abst/Vehicle, $n=6$; Ext/Vehicle, $n=6$; Abst/CDPPB, $n=6$; Ext/CDPPB, $n=7$ ). Post hoc analysis further revealed that extinction training alone significantly increased the mean peak amplitude of the eNMDA current (Abst/Vehicle vs Ext/Vehicle; $p=0.033$ ). Interestingly, administration of CDPPB completely prevented this extinctioninduced increase in eNMDA currents. This was observed as a significant reduction in the amplitude of the eNMDA current in the Ext/CDPPB group compared with the Ext/ Vehicle group $(p=0.036)$. As expected, the input-output curves for stimulation intensity in abstinent rats were not significantly different between the Abst/Vehicle and Abst/CDPPB groups (Fig. $\left.5 B ; F_{(9,80)}=0.2, p>0.05\right)$. However, there was a significant treatment $\times$ stimulus intensity interaction $\left(F_{(9,100)}\right.$ $=2.0, p=0.049$ ) in the input/output recording obtained from rats exposed to extinction training (Ext/Vehicle vs Ext/ CDPPB; Fig. $5 C$ ). This was observed as significantly higher amplitude at higher stimulus intensities $(70 \mu \mathrm{A}: p=0.033$, $t_{(100)}=2.9 ; 80 \mu \mathrm{A}: p=0.013, t_{(100)}=3.2 ; 90 \mu \mathrm{A}: p=0.007$, $t_{(100)}=3.5$; and $\left.100 \mu \mathrm{A}: p<0.007, t_{(100)}=3.5\right)$.

In the IfL cortex, analysis of eNMDA currents obtained from the same treatment groups (Abst/Vehicle, $n=6$; Ext/Vehicle, $n=$ 6; Abst/CDPPB, $n=6$; Ext/CDPPB, $n=7$; Fig. 5D) again revealed a main treatment effect of extinction $\left(F_{(1,19)}=5.2, p=\right.$ 0.035). However, post hoc comparison of the individual group did not reveal any significant group differences. Consistent with this, there were no significant differences in the input-output relationships for vehicle compared with CDPPB in either the $\operatorname{Abst}\left(F_{(9,80)}=\right.$ $0.7, p>0.05$; Fig. $5 E)$ or Ext groups $\left(F_{(9,110)}=0.1, p>0.05\right.$; Fig. $\left.5 F\right)$. 
The next set of analyses examined changes in eAMPA currents measured at a holding potential of $-80 \mathrm{mV}$. As shown in Figure $6 A$, there was a significant main effect of training $\left(F_{(1,16)}=8.4, p=0.011\right)$ in the PrL cortex, but no main effect of treatment $\left(F_{(1,16)}=0.5, p>0.05\right)$ or a training $\times$ treatment interaction $\left(F_{(1,16)}=0.0\right.$, $p>0.05 ; n=6$ for all groups). Post hoc analysis of the individual groups indicated that there were no significant differences. Consistent with this, there were no significant differences in the input-output relationships for eAMPA currents for vehicle compared with CDPPB in either the Abst $\left(F_{(9,50)}=0.4, p>0.05\right)$ or Ext $F_{(9,50)}=$ $0.1, p>0.05)$ groups in the PrL cortex (Fig. $6 B, C$ ). In the IfL cortex, neither training $\left(F_{(1,19)}=0.2, p>0.05\right)$ nor treatment $\left(F_{(1,19)}=0.4, p>0.05\right)$ had an effect on the amplitude of eAMPA currents $(n=$ 6 for all groups; Fig. 6D). Similarly, no differences were observed in the inputoutput relationships for IfL eAMPA currents in slices from $\operatorname{Abst}\left(F_{(9,90)}=0.1, p>\right.$ $0.05)$ or Ext rats $\left(F_{(9,90)}=0.1, p>0.05\right.$; Fig. $6 E, F)$.

To determine whether the amplitude of eAMPA currents recorded in PrL and IfL were significantly different, we compared the size of the eAMPA currents obtained from ethanol-naive rats with the amplitude of currents of the Abst/Vehicle and Ext/Vehicle groups shown in Figure $6, A$ and $B$. This analysis revealed that there were no significant differences in the amplitude of eAMPA currents in PrL cortex compared with IfL cortex for any of these groups $\left(F_{(2,25)}=2.044, p>0.05\right)$. In addition, as a complementary measure to the analysis of the amplitude of the isolated eNMDA and eAMPA currents, we also calculated the AMPA/NMDA current ratio for the four experimental groups in Figures 5 and 6 (data not shown). In the PrL cortex, there was a significant reduction in the AMPA/ NMDA ratio for the Ext/Vehicle $(1.9 \pm 0.40)$ compared with Abst/Vehicle $(3.9 \pm 0.69)$ groups $\left(t_{(14)}=2.661, p=0.009\right)$. The AMPA/NMDA current ratio for Ext/Vehicle (1.9 \pm 0.40$)$ compared with Ext/CDPPB was higher for Ext/CDPPB (3.4 \pm 0.84$)$, as expected, but did not quite reach statistical significance $\left(t_{(19)}=\right.$ $1.603, p=0.06)$. There were no significant differences observed in the AMPA/NMDA ratio for any other group mean comparisons in either the PrL or IfL cortex.

It is well known that AMPA currents of receptors that contain the GluR2 subunit are nonrectifying and impermeable to calcium, whereas currents from AMPA receptors that lack GluR2 subunits are rectifying and calcium permeable. Therefore, in the next set of studies, we investigated whether either extinction or CDPPB altered AMPA current rectification. Consistent with GluR2 containing AMPA receptors, eAMPA currents recorded in the IfL cortex of vehicle-treated control slices were nonrectifying and exhibited a near linear $I-V$ relationship (Fig. 7A). However, eAMPA currents recording from the CDPPB-treated rats were rectifying and exhibited a nonlinear $I-V$ relationship, indicating

\section{IfL AMPA}

Vehicle

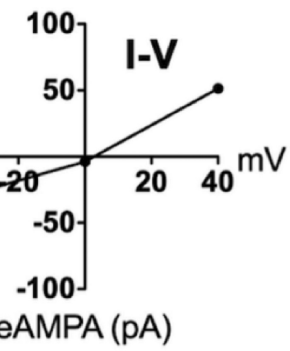

IfL AMPA RI

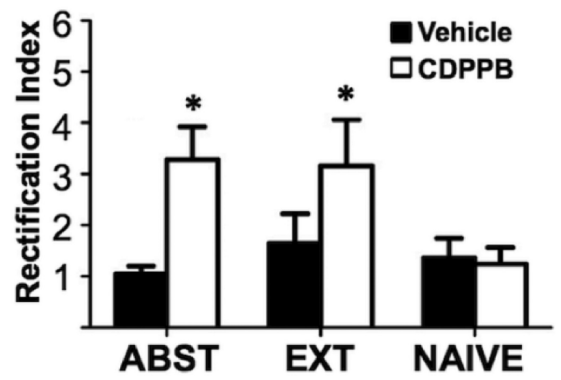

Figure 7. CDPPB induces the formation of calcium-permeable AMPA receptors in the IfL only in rats with a history of ethanol self-administration. Rats were trained to self-administer ethanol using an ethanol pre-exposure paradigm and then administered cortex. Asterisk indicates significant difference from the respective vehicle control for ABST $(p=0.004)$ and EXT $(p=0.048)$ groups ( $n=6$ for all groups except CDPPB/Naive, $n=8$ ).

that $\mathrm{CDPPB}$ treatment resulted in formation of calciumpermeable, GluR2-lacking AMPA receptors in IfL pyramidal neurons. To provide a quantitative measure of the changes in the kinetics of the AMPA currents in the different treatment groups, a rectification index (RI) was calculated as the ratio of the slope of the IV curve at negative and positive holding potentials for both the IfL (Fig. $7 B$ ) and the PrL (Fig. $7 C$ ) cortex. In the IfL cortex, CDPPB treatment resulted in a significant increase $\left(F_{(2,29)}=3.9\right.$, $p=0.032 ; n=6$ for all groups) in the RI in rats that had experienced either abstinence $(p=0.002)$ or extinction $(p=0.043)$. In a follow-up set of experiments, we investigated the effects CDPPB treatment in a group of naive rats that had no previous experience with operant self-administration of ethanol (Fig. $7 B$ ). In these rats, CDPPB had no effect on the RI ( $p>0.05 ; n=8)$, indicating that CDPPB promoted the formation of calcium-permeable AMPA receptors in the IfL cortex only in rats that had a previous history of ethanol self-administration. In contrast to CDPPBinduced expression of calcium-permeable AMPA receptors in the IfL cortex, there was no effect of treatment $\left(F_{(1,16)}=0.0, p>\right.$ $0.05)$, training $\left(F_{(1,16)}=0.3, p>0.05\right)$, or a treatment $\times$ training interaction $\left(F_{(1,16)}=0.1, p>0.05 ; n=6\right.$ for all groups $)$ on the RI in pyramidal neurons of the PrL cortex (Fig. $7 C$ ). 

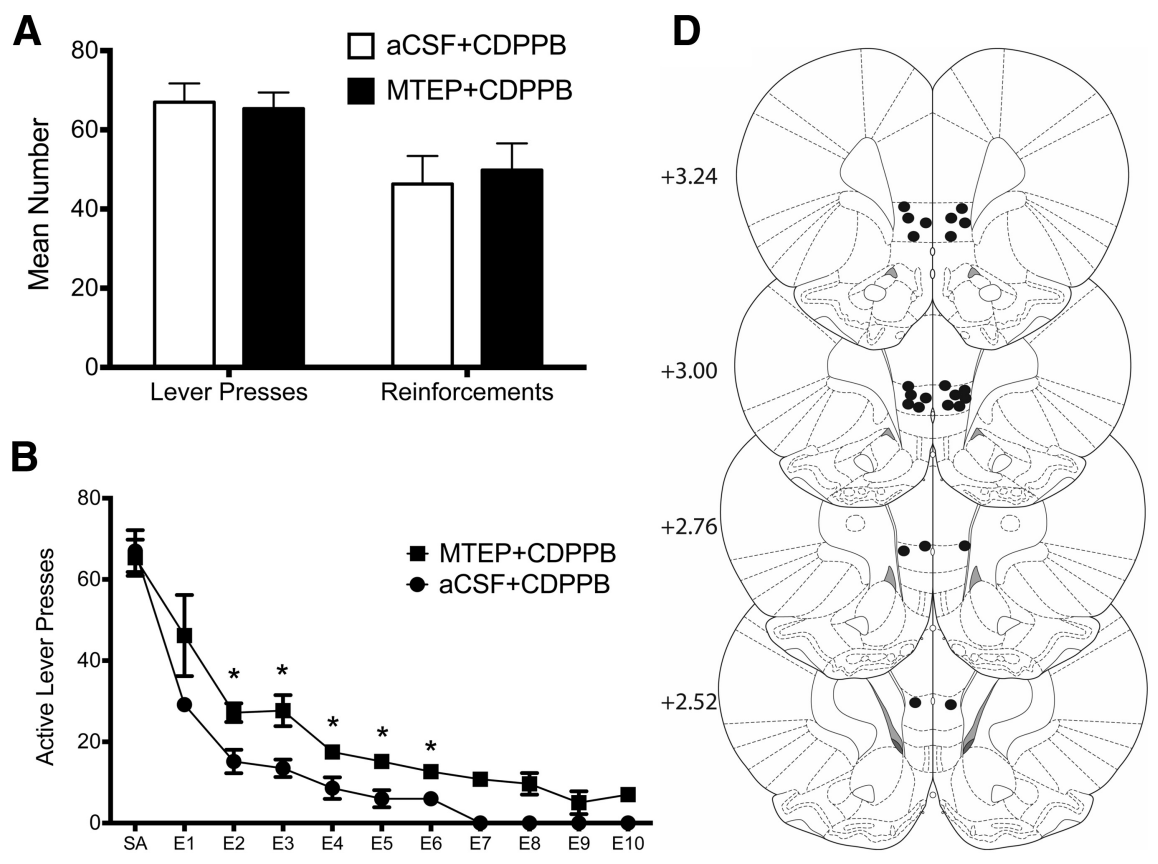

C

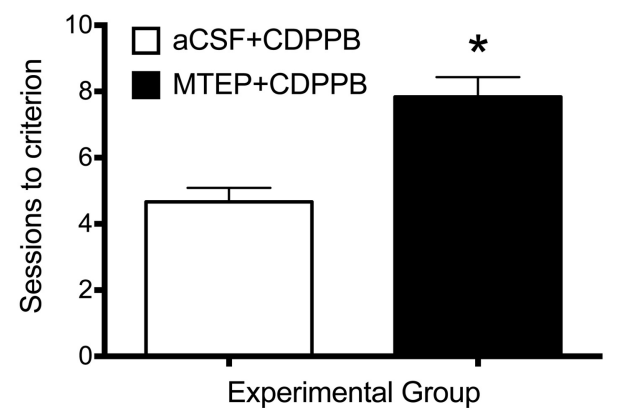

$\mathbf{E}$

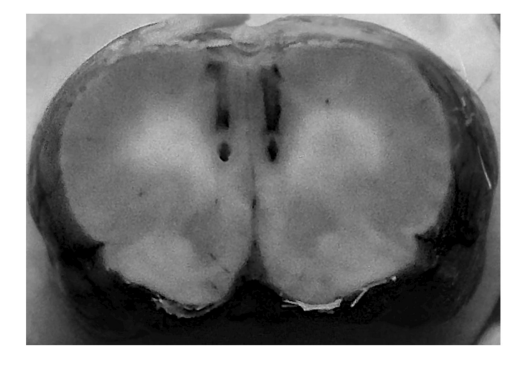

Figure 8. Local administration of MTEP into the IfL cortex during extinction training prevented the facilitating effects of CDPPB on extinction learning. Rats from this experiment were trained to self-administer ethanol using the ethanol pre-exposure technique (the average ethanol consumption for a 30 min session was $0.94 \mathrm{~g} / \mathrm{kg}$ ). $\boldsymbol{A}$, Before extinction training, there were no differences between the two groups in ethanol self-administration $(p>0.05)$. $\boldsymbol{B}$, Treatment with MTEP before each daily extinction session resulted in a significant treatment $\times$ session interaction $(p=0.011 ; n=6)$. Post hoc analyses revealed that rats treated with MTEP had significantly more responses on the previously active lever compared with vehicle-treated rats on multiple extinction sessions. ${ }^{*} p<0.006$. $B, \boldsymbol{C}$, Rats treated with MTEP before CDPPB administration also required significantly more extinction sessions to reach extinction criteria compared with vehicle-treated rats $(p=0.002)$. $\boldsymbol{D}$, Diagram of coronal rat brain sections showing the location of microinjector tips (dark circles) in the IfL cortex. Illustrations were adapted from the atlas of Paxinos and Watson (2005). The numbers along the left side of each section represent the distance (in millimeters of that section from bregma. $\boldsymbol{E}$, Representative photomicrograph showing the injection site into the IfL cortex.

\section{Microinjection studies}

The preceding studies showed that CDPPB facilitation of extinction was associated with the formation of calcium-permeable AMPA receptors specifically in the IfL cortex. Therefore, in the next set of studies, we investigated whether CDPPB facilitation of extinction was dependent upon activation of mGluR5 receptors selectively in this brain area. For these experiments, we perfused the mGluR5 antagonist MTEP locally within the IfL cortex immediately before CDPPB administration during each daily extinction session. As shown in Figure 8A, there were no differences in the number of active lever represses or total number of ethanol reinforcements between the two groups of rats before extinction training. However, local administration of MTEP into the IfL cortex before CDPPB resulted in a significant treatment $\times$ session interaction $\left(F_{(10,100)}=2.5, p=0.011 ; n=6\right.$; Fig. $\left.8 B\right)$. Post hoc analyses further revealed that rats treated with MTEP had significantly more responses on the previously active lever compared with vehicletreated rats on multiple extinction sessions $(p<0.006)$. Rats treated with MTEP also required significantly more extinction sessions to reach extinction criteria compared with vehicle-treated rats $\left(t_{(39)}=9.7, p=0.001\right.$; Fig. $\left.8 C\right)$. Histological examination of the site of the injection revealed that all injections were within the IfL cortex or its boundary regions (Fig. $8 D$ ) and did not result in any visible signs of tissue damage (Fig. 8E).

In a separate set of rats, we next examined the effect of local administration of MTEP into the PrL cortex during CDPPB-facilitated extinction training. Again, there were no differences in ethanol self-administration or number of ethanol reinforcements before extinction training (Fig. 9A). However, unlike the effects observed in the IfL cortex, microinjection of MTEP into the PrL cortex had no effect on CDPPB facilitation of extinction (Fig. 9B). Specifically, there was no treatment $\times$ session interaction $\left(F_{(4,40)}=\right.$ $0.3, p>0.05 ; n=6)$. Rats microinjected with MTEP before CDPPB administration did not differ from the Vehicle/CDPPB group in the number of extinction sessions to reach extinction criteria $\left(t_{(10)}\right.$ $=0.5, p>0.05$; Fig. 9C). Histological examination of the site of the injection demonstrated that all injections were within the PrL cortex or its boundary regions (Fig. 9D). Together, these results provide strong support for a critical role of mGluR5 receptor activity in the IfL cortex in the facilitating actions of CDPPB on the extinction of ethanol-seeking behavior.

\section{Discussion}

These findings demonstrate that modulation of mGluR5 by CDPPB facilitates the extinction of ethanol-seeking behavior, as indicated by a reduction in active lever responding during extinction, fewer required extinction sessions, and attenuation of cueinduced reinstatement. Extinction learning was associated with changes in structural and functional plasticity of glutamatergic neurotransmission in the PrL and IfL cortex, consistent with previous studies implicating these subregions in the extinction of conditioned behavior (Quirk et al., 2006; Peters et al., 2009). A particularly interesting observation was that daily administration of CDPPB resulted in the conversion of AMPA currents from nonrectifying (calcium-impermeable) to rectifying (calciumpermeable) in the IfL cortex, but was without effect on AMPA current rectification in the PrL cortex. Therefore, mGluR5mediated formation of calcium-permeable AMPA receptors in the IfL cortex may promote plasticity processes that enhance extinction learning. This is consistent with a recent report that the extinction of fear behavior is also associated with the formation of 
calcium-permeable AMPA receptors in the IfL cortex (Sepulveda-Orengo et al., 2013).

Extinction creates a new inhibitory memory trace that is different from the original association memory (Rescorla, 2004). The result is competition between this newly acquired memory and the original association for control of behavior. As extinction training progresses, strengthening of this new inhibitory association is observed as a reduction in conditioned responding. Our observation that potentiation of mGluR5 enhanced extinction of ethanol seeking, together with our previous studies showing that CDPPB enhanced extinction of cocaine-seeking behavior (Gass and Olive, 2009; Cleva et al., 2011), are consistent with an enhancement of a new competing extinction memory trace. In addition, CDPPB facilitation of extinction responding is experience-dependent learning. We show that responding during the initial period of the extinction session (when the expected reinforcer is not received) was not altered by CDPPB on day 1 of extinction, but initial responding was decreased on day 2 of extinction, suggesting an inhibition of responding due to lack of ethanol delivery. In agreement with a previous study involving extinction of cocaine selfadministration (Cleva et al., 2011), these data also indicated that CDPPB facilitation of extinction learning is not the result of altered locomotor activity.

Electrophysiological studies in acute slice preparations suggested that both extinction learning and mGluR5-mediated facilitation of extinction are associated with differential changes in glutamate receptor signaling within the PrL and IfL cortex. These observations are consistent with studies demonstrating that modulation of glutamatergic transmission can facilitate extinction learning of drug-related memories (Botreau et al., 2006; Leslie et al., 2012, but see Lu et al., 2011). Furthermore, we observed that CDPPB facilitation of extinction of ethanol self-administration was associated with attenuation of NMDA receptor currents in the PrL cortex, consistent with the observation that inactivation of the PrL cortex suppresses cocaine seeking (LaLumiere and Kalivas, 2008). One possible mechanism by which CDPPB facilitates extinction learning is through indirect stimulation of NMDA receptors (Marino and Conn, 2002). However, because activation of mGluR5 is associated with enhanced NMDA receptor signaling, it is unclear why CDPPB-facilitated extinction would promote attenuation of NMDA currents in the PrL cortex. Although speculative, this may have involved a compensatory downregulation of mGluR5 receptors or uncoupling of their signaling, because repeated activation of mGluR5 in the frontal cortex has been reported to decrease the density of mGluR5 receptors and to alter their ability to promote NMDA receptor expression (Parmentier-Batteur et al., 2012). Why this would occur in the PrL and not IfL cortex could relate to the differential roles of these two regions in extinction learning.

In contrast to the PrL cortex, inactivation of the IfL cortex has been shown to promote reinstatement of drug seeking (Ovari and Leri, 2008; Peters et al., 2008a). Whereas CDPPB-facilitated extinction was not associated with changes in the amplitude of AMPA receptor-mediated currents in either the PrL or IfL cortex, there was a change in the rectification properties of AMPA currents in the IfL cortex only. This change in kinetic properties of the AMPA channels is consistent with a shift from calciumimpermeable, GluR2-containing AMPA receptors to calciumpermeable, GluR2-lacking receptors (or a change in editing of the Q/R site for GluR2). Removal of the GluR2 subunit from the synaptic membrane promotes enhanced synaptic plasticity as a result of an increase in calcium influx through the channels (Man, 2011) and it is likely that the CDPPB-induced shift in the calcium permeability of AMPA receptors in the IfL cortex may 
facilitate the formation of an extinction memory trace. Extinction of fear increases the AMPA RI, and this effect is prevented with mGluR5 blockade (Sepulveda-Orengo et al., 2013). The role of mGluR5 and the IfL cortex in the extinction of conditioned ethanol-seeking behavior is further supported by the results of our microinjection studies using an mGluR5 antagonist. Local administration of MTEP into the IfL cortex blocked the facilitating actions of CDPPB, but had no effect on CDPPB facilitation of extinction when injected into the PrL cortex.

Changes in the morphology and density of dendritic spines reflect alterations in plasticity and synaptic transmission (Chandler, 2003; Mulholland and Chandler, 2007). Dendritic spines are also mediators of synaptic stability underlying learning and memory processes and spine changes have been observed after extinction learning. Consistent with this, we observed that extinction training and CDPPB facilitation of extinction was not only associated with functional alterations in NMDA and AMPA receptors in the PrL and IfL cortex, but also with differential changes in structural plasticity in these regions. There was an increase in mushroom spine density in the IfL cortex and long spines in the PrL cortex. Morphological changes in dendritic spines occur through experience-dependent processes and growth/retraction of dendritic spines with synapse formation and elimination could contribute to and/or reflect alterations in plasticity during extinction learning (Holtmaat et al., 2006). Although the contribution of these spine changes to extinction learning is unknown, they indicate that CDPPB-facilitated extinction is associated with alterations in plasticity within brain regions implicated in extinction learning. It is of interest that LTP-inducing protocols have been shown to result in the initial insertion and perisynaptic localization of calcium-permeable GluR2-lacking AMPA receptors that promote a labile increase in spine size (Yang et al., 2010). As LTP proceeds, the GluR2-lacking receptors are trafficked to the synapse and then replaced by GluR2-containing receptors that stabilize spine enlargement. Our observation of CDPPB-induced formation of GluR2-lacking receptors in the IfL cortex is generally consistent with this model. We suggest that CDPPB produces a permissive state of synaptic plasticity that is engaged during extinction learning, leading to increased formation of larger and more stable mushroom spines in association with extinction-specific synaptic inputs in the IfL cortex.

A challenge in successful intervention of addiction is the high incidence of relapse. Therefore, it is highly desirable that newly identified therapeutic targets also reduce relapse-like behavior. Previous studies examining the effectiveness of DCS in reducing reinstatement of drug seeking have yielded mixed results (Paolone et al., 2009; Torregrossa et al., 2010; Lu et al., 2011). This is the first study to demonstrate that targeting mGluR5 with a PAM both facilitated extinction of ethanol seeking and attenuated cue-induced reinstatement of ethanol seeking. Together, these results provide strong preclinical support for the therapeutic potential of PAMs of mGluR5 in the treatment of alcoholism. Future studies are needed to further characterize the effect of CDPPB on ethanol seeking, including an examination of its effect on contextual reinstatement and spontaneous recovery.

An alternative explanation to CDPPB-facilitated extinction learning is that it instead disrupted reconsolidation memory (Sorg, 2012). Conditioned stimulus presentation initiates a temporary labile state during which changes to the original association with the unconditioned stimulus can occur. Pharmacological actions of CDPPB during this state may have disrupted the original memory and ultimately affected conditioned behavior. However, we think this is unlikely because reconsoli- dation studies typically require short presentations of the conditioned stimulus (Nader and Hardt, 2009) and CDPPB has mnemonic benefits (Ayala et al., 2009). In addition, CDPPB treatment may have promoted the "forgetting" of the previously learned memory. We again feel that this is unlikely because CDPPB and other mGluR5 PAMs produce procognitive effects and enhanced plasticity (Gass and Olive, 2009; Kroker et al., 2011; Fowler et al., 2013; Xu et al., 2013). However, the possibility that a combination of these processes contributed to the effects of CDPPB on extinction of ethanol seeking cannot be excluded. In addition, further studies are required to determine whether CDPPB administration is effective in the absence of extinction (abstinence). Similar studies have shown that DCS is effective only when combined with extinction (Torregrossa et al., 2010); however, other studies have shown that the peptide ZIP results in memory erasure without extinction training (Shema et al., 2007).

In summary, the results of the present study demonstrated that PAM of mGluR5 with CDPPB facilitates the acquisition of extinction learning after ethanol self-administration. In addition, extinction was associated with differential changes in the structure and function of glutamatergic-based plasticity in the PrL and IfL cortices. Given the ineffectiveness of exposure therapy, these findings suggest that mGluR5 PAMs such as CDPPB may serve as a pharmacological enhancement to exposure therapy, possibly through actions within PFC, and ultimately reduce relapse in alcoholics.

\section{References}

Ayala JE, Chen Y, Banko JL, Sheffler DJ, Williams R, Telk AN, Watson NL, Xiang Z, Zhang Y, Jones PJ, Lindsley CW, Olive MF, Conn PJ (2009) mGluR5 positive allosteric modulators facilitate both hippocampal LTP and LTD and enhance spatial learning. Neuropsychopharmacology 34: 2057-2071. CrossRef Medline

Bossert JM, Stern AL, Theberge FR, Cifani C, Koya E, Hope BT, Shaham Y (2011) Ventral medial prefrontal cortex neuronal ensembles mediate context-induced relapse to heroin. Nat Neurosci 14:420-422. CrossRef Medline

Bossert JM, Stern AL, Theberge FR, Marchant NJ, Wang HL, Morales M, Shaham Y (2012) Role of projections from ventral medial prefrontal cortex to nucleus accumbens shell in context-induced reinstatement of heroin seeking. J Neurosci 32:4982-4991. CrossRef Medline

Botreau F, Paolone G, Stewart J (2006) d-Cycloserine facilitates extinction of a cocaine-induced conditioned place preference. Behav Brain Res 172: 173-178. CrossRef Medline

Capriles N, Rodaros D, Sorge RE, Stewart J (2003) A role for the prefrontal cortex in stress- and cocaine-induced reinstatement of cocaine seeking in rats. Psychopharmacology 168:66-74. CrossRef Medline

Chandler LJ (2003) Ethanol and brain plasticity: receptors and molecular networks of the postsynaptic density as targets of ethanol. Pharmacol Ther 99:311-326. CrossRef Medline

Childress AR, Hole AV, Ehrman RN, Robbins SJ, McLellan AT, O’Brien CP (1993) Cue reactivity and cue reactivity interventions in drug dependence. NIDA Res Monogr 137:73-95. Medline

Cleva RM, Hicks MP, Gass JT, Wischerath KC, Plasters ET, Widholm JJ, Olive MF (2011) mGluR5 positive allosteric modulation enhances extinction learning following cocaine self-administration. Behav Neurosci 125:10-19. CrossRef Medline

Conklin CA, Tiffany ST (2002) Cue-exposure treatment: time for change. Addiction 97:1219-1221. CrossRef Medline

Di Pietro NC, Black YD, Kantak KM (2006) Context-dependent prefrontal cortex regulation of cocaine self-administration and reinstatement behaviors in rats. Eur J Neurosci 24:3285-3298. CrossRef Medline

Fanous S, Goldart EM, Theberge FR, Bossert JM, Shaham Y, Hope BT (2012) Role of orbitofrontal cortex neuronal ensembles in the expression of incubation of heroin craving. J Neurosci 32:11600-11609. CrossRef Medline

Feltenstein MW, See RE (2006) Potentiation of cue-induced reinstatement of cocaine-seeking in rats by the anxiogenic drug yohimbine. Behav Brain Res 174:1-8. CrossRef Medline 
Fowler SW, Walker JM, Klakotskaia D, Will MJ, Serfozo P, Simonyi A, Schachtman TR (2013) Effects of a metabotropic glutamate receptor 5 positive allosteric modulator, CDPPB, on spatial learning task performance in rodents. Neurobiol Learn Mem 99:25-31. CrossRef Medline

Fuchs RA, Branham RK, See RE (2006) Different neural substrates mediate cocaine seeking after abstinence versus extinction training: a critical role for the dorsolateral caudate-putamen. J Neurosci 26:3584-3588. CrossRef Medline

Gass JT, Olive MF (2009) Positive allosteric modulation of mGluR5 receptors facilitates extinction of a cocaine contextual memory. Biol Psychiatry 65:717-720. CrossRef Medline

Gass JT, Sinclair CM, Cleva RM, Widholm JJ, Olive MF (2011) Alcohol-seeking behavior is associated with increased glutamate transmission in basolateral amygdala and nucleus accumbens as measured by glutamate-oxidase-coated biosensors. Addiction Biology 16:215-228. CrossRef Medline

Holtmaat A, Wilbrecht L, Knott GW, Welker E, Svoboda K (2006) Experience-dependent and cell-type-specific spine growth in the neocortex. Nature 441:979-983. CrossRef Medline

Kalivas PW, Peters J, Knackstedt L (2006) Animal models and brain circuits in drug addiction. Mol Interv 6:339-344. CrossRef Medline

Kaplan GB, Moore KA (2011) The use of cognitive enhancers in animal models of fear extinction. Pharmacology, Biochemistry, and Behavior 99:217-228. CrossRef Medline

Kinney GG, O’Brien JA, Lemaire W, Burno M, Bickel DJ, Clements MK, Chen TB, Wisnoski DD, Lindsley CW, Tiller PR, Smith S, Jacobson MA, Sur C, Duggan ME, Pettibone DJ, Conn PJ, Williams DL Jr (2005) A novel selective positive allosteric modulator of metabotropic glutamate receptor subtype 5 has in vivo activity and antipsychotic-like effects in rat behavioral models. J Pharmacol Exp Ther 313:199-206. CrossRef Medline

Kroener S, Mulholland PJ, New NN, Gass JT, Becker HC, Chandler LJ (2012) Chronic alcohol exposure alters behavioral and synaptic plasticity of the rodent prefrontal cortex. PLoS One 7:e37541. CrossRef Medline

Kroker KS, Rast G, Rosenbrock H (2011) Differential effect of the mGlu5 receptor positive allosteric modulator ADX-47273 on early and late hippocampal LTP. Neuropharmacology 61:707-714. CrossRef Medline

LaLumiere RT, Kalivas PW (2008) Glutamate release in the nucleus accumbens core is necessary for heroin seeking. J Neurosci 28:3170-3177. CrossRef Medline

LaLumiere RT, Niehoff KE, Kalivas PW (2010) The infralimbic cortex regulates the consolidation of extinction after cocaine self-administration. Learn Mem 17:168-175. CrossRef Medline

Leslie JC, Norwood K, Kennedy PJ, Begley M, Shaw D (2012) Facilitation of extinction of operant behaviour in C57BL/6 mice by chlordiazepoxide and D-cycloserine. Psychopharmacology.

Lindsley CW, Wisnoski DD, Leister WH, O'Brien JA, Lemaire W, Williams DL Jr, Burno M, Sur C, Kinney GG, Pettibone DJ, Tiller PR, Smith S, Duggan ME, Hartman GD, Conn PJ, Huff JR (2004) Discovery of positive allosteric modulators for the metabotropic glutamate receptor subtype 5 from a series of $\mathrm{N}$-(1,3-diphenyl-1H-pyrazol-5-yl)benzamides that potentiate receptor function in vivo. J Med Chem 47:5825-5828. CrossRef Medline

Lu GY, Wu N, Zhang ZL, Ai J, Li J (2011) Effects of D-cycloserine on extinction and reinstatement of morphine-induced conditioned place preference. Neurosci Lett 503:196-199. CrossRef Medline

Man HY (2011) GluA2-lacking, calcium-permeable AMPA receptors-inducers of plasticity? Curr Opin Neurobiol 21:291-298. CrossRef Medline

Marino MJ, Conn PJ (2002) Direct and indirect modulation of the $\mathrm{N}$-methyl D-aspartate receptor. Current Drug Targets CNS and Neurological Disorders 1:1-16. CrossRef Medline

McFarland K, Kalivas PW (2001) The circuitry mediating cocaine-induced reinstatement of drug-seeking behavior. J Neurosci 21:8655-8663. Medline

Milad MR, Quirk GJ (2012) Fear extinction as a model for translational neuroscience: ten years of progress. Annu Rev Psychol 63:129-151. CrossRef Medline

Millan EZ, Marchant NJ, McNally GP (2011) Extinction of drug seeking. Behav Brain Res 217:454-462. CrossRef Medline

Mulholland PJ, Chandler LJ (2007) The thorny side of addiction: adaptive plasticity and dendritic spines. ScientificWorldJournal 7:9-21. CrossRef Medline

Nader K, Hardt O (2009) A single standard for memory: the case for reconsolidation. Nat Rev Neurosci 10:224-234. CrossRef Medline

Ovari J, Leri F (2008) Inactivation of the ventromedial prefrontal cortex mimics re-emergence of heroin seeking caused by heroin reconditioning. Neurosci Lett 444:52-55. CrossRef Medline
Paolone G, Botreau F, Stewart J (2009) The facilitative effects of D-cycloserine on extinction of a cocaine-induced conditioned place preference can be long lasting and resistant to reinstatement. Psychopharmacology 202:403-409. CrossRef Medline

Parmentier-Batteur S, O’Brien JA, Doran S, Nguyen SJ, Flick RB, Uslaner JM, Chen H, Finger EN, Williams TM, Jacobson MA, Hutson PH (2012) Differential effects of the mGluR5 positive allosteric modulator CDPPB in the cortex and striatum following repeated administration. Neuropharmacology 62:1453-1460. CrossRef Medline

Paxinos G, Watson C (2005) The rat brain in stereotaxic coordinates, Ed 5. San Diego: Academic.

Peters J, LaLumiere RT, Kalivas PW (2008a) Infralimbic prefrontal cortex is responsible for inhibiting cocaine seeking in extinguished rats. J Neurosci 28:6046-6053. CrossRef Medline

Peters J, Vallone J, Laurendi K, Kalivas PW (2008b) Opposing roles for the ventral prefrontal cortex and the basolateral amygdala on the spontaneous recovery of cocaine-seeking in rats. Psychopharmacology 197:319326. CrossRef Medline

Peters J, Kalivas PW, Quirk GJ (2009) Extinction circuits for fear and addiction overlap in prefrontal cortex. Learn Mem 16:279-288. CrossRef Medline

Quirk GJ, Garcia R, González-Lima F (2006) Prefrontal mechanisms in extinction of conditioned fear. Biol Psychiatry 60:337-343. CrossRef Medline

Ranaldi R, Roberts DC (1996) Initiation, maintenance and extinction of cocaine self-administration with and without conditioned reward. Psychopharmacology 128:89-96. CrossRef Medline

Reichel CM, Schwendt M, McGinty JF, Olive MF, See RE (2011) Loss of object recognition memory produced by extended access to methamphetamine self-administration is reversed by positive allosteric modulation of metabotropic glutamate receptor 5. Neuropsychopharmacology 36:782792. CrossRef Medline

Rescorla RA (2004) Spontaneous recovery. Learn Mem 11:501-509. CrossRef Medline

Rogers JL, Ghee S, See RE (2008) The neural circuitry underlying reinstatement of heroin-seeking behavior in an animal model of relapse. Neuroscience 151:579-588. CrossRef Medline

Samson HH (1986) Initiation of ethanol reinforcement using a sucrosesubstitution procedure in food- and water-sated rats. Alcoholism, Clinical and Experimental Research 10:436-442. CrossRef Medline

Schmidt EF, Sutton MA, Schad CA, Karanian DA, Brodkin ES, Self DW (2001) Extinction training regulates tyrosine hydroxylase during withdrawal from cocaine self-administration. J Neurosci 21:RC137. Medline

See RE (2005) Neural substrates of cocaine-cue associations that trigger relapse. Eur J Pharmacol 526:140-146. CrossRef Medline

Self DW, Choi KH, Simmons D, Walker JR, Smagula CS (2004) Extinction training regulates neuroadaptive responses to withdrawal from chronic cocaine self-administration. Learn Mem 11:648-657. CrossRef Medline

Sepulveda-Orengo MT, Lopez AV, Soler-Cedeño O, Porter JT (2013) Fear extinction induces mGluR5-mediated synaptic and intrinsic plasticity in infralimbic neurons. J Neurosci 33:7184-7193. CrossRef Medline

Shema R, Sacktor TC, Dudai Y (2007) Rapid erasure of long-term memory associations in the cortex by an inhibitor of PKM zeta. Science 317:951953. CrossRef Medline

Shen HW, Toda S, Moussawi K, Bouknight A, Zahm DS, Kalivas PW (2009) Altered dendritic spine plasticity in cocaine-withdrawn rats. J Neurosci 29:2876-2884. CrossRef Medline

Sinclair CM, Cleva RM, Hood LE, Olive MF, Gass JT (2012) mGluR5 receptors in the basolateral amygdala and nucleus accumbens regulate cueinduced reinstatement of ethanol-seeking behavior. Pharmacol Biochem Behav 101:329-335. CrossRef Medline

Sorg BA (2012) Reconsolidation of drug memories. Neurosci Biobehav Rev 36:1400-1417. CrossRef Medline

Torregrossa MM, Sanchez H, Taylor JR (2010) D-cycloserine reduces the context specificity of Pavlovian extinction of cocaine cues through actions in the nucleus accumbens. J Neurosci 30:10526-10533. CrossRef Medline

Xu J, Zhu Y, Kraniotis S, He Q, Marshall JJ, Nomura T, Stauffer SR, Lindsley CW, Conn PJ, Contractor A (2013) Potentiating mGluR5 function with a positive allosteric modulator enhances adaptive learning. Learn Mem 20:438-445. CrossRef Medline

Yang Y, Wang XB, Zhou Q (2010) Perisynaptic GluR2-lacking AMPA receptors control the reversibility of synaptic and spines modifications. Proc Natl Acad Sci U S A 107:11999-12004. CrossRef Medline 